\title{
Bubble Dynamics and Nucleate Pool Boiling Heat Transfer on
}

\section{Microporous Copper Surfaces}

\author{
Suraj Joottu Thiagarajan ${ }^{1, \mathrm{a}}$, Ronggui Yang ${ }^{1, \mathrm{~b}}$, Charles King ${ }^{2, \mathrm{c}}$, Sreekant Narumanchi ${ }^{2, \mathrm{~d}}$ \\ ${ }^{1}$ Department of Mechanical Engineering, University of Colorado, Boulder, CO, 80309, USA \\ ${ }^{2}$ National Renewable Energy Laboratory, 15013 Denver West Parkway, Golden, CO, 80401, \\ USA \\ ${ }^{a}$ Suraj.Thiagarajan@Colorado.Edu Phone: 720-505-9517

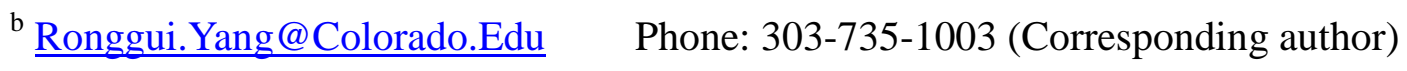 \\ ${ }^{\mathrm{c}}$ Charles.King@NREL.gov $\quad$ Phone: 303-275-4419 \\ ${ }^{\mathrm{d}}$ Sreekant.Narumanchi@ NREL.gov Phone: 303-275-4062 (Corresponding author)
}

\begin{abstract}
Nucleate pool boiling experiments were performed on microporous copper surfaces and plain surfaces using saturated HFE-7100 as the working fluid. Quantitative measurements of the bubble dynamics, such as the nucleation site density, bubble diameter at departure, and bubble departure frequency, were obtained using high-speed visualization. The microporous surfaces, with coating thicknesses in the range of $100 \mu \mathrm{m}$ to $700 \mu \mathrm{m}$, porosity of $55 \%$ to $60 \%$, and cavity sizes in the range of $0.5 \mu \mathrm{m}$ to $5 \mu \mathrm{m}$, showed a significantly lower boiling incipience temperature, which enhanced the heat transfer coefficient by $50 \%$ to $270 \%$ and enhanced the critical heat fluxes by $33 \%$ to $60 \%$ when compared to the plain surface. At low heat flux levels, the surface with a thicker microporous coating showed better performance than the thinner one. However, the thinner microporous coating resulted in higher critical heat flux than the thicker surface. The site density, departure diameter, and departure frequency were compared against the
\end{abstract}


predictions using various correlations from the literature. Based on a heat flux partition model, using the measured values of the active site density and bubble departure diameter and frequency, and neglecting the single-phase heat transfer effects of bubble coalescence, the individual modes of heat transfer (evaporative, quenching, and convective) were computed. Reasonably good agreement between the partition model results and the experimental data was obtained. On the plain surfaces, the evaporative and quenching components were approximately equal. On the microporous surfaces, the evaporative component was found to be significantly higher.

\section{Keywords}

power electronics cooling; pool boiling; surface enhancements; microporous surface; HFE-7100

\section{Nomenclature}

$\begin{array}{ll}A & \text { area of target surface } \\ C_{P} & \text { specific heat of liquid at constant pressure } \\ D & \text { diameter of bubbles at departure } \\ D_{c r i t} & \text { critical diameter of nucleating cavity at given wall superheat } \\ f & \text { frequency of bubble departure from a site } \\ h_{l v} & \text { latent heat of vaporization } \\ h & \text { heat transfer coefficient } \\ k & \text { thermal conductivity of copper } \\ k_{l} & \text { thermal conductivity of liquid } \\ l_{l 2} & \text { distance between the two thermocouple locations } \\ l_{l w} & \text { distance between the first thermocouple and target surface } \\ l_{2 w} & \text { distance between the second thermocouple and target surface } \\ L_{c} & \text { capillary length of the liquid } \\ L_{h} & \text { target surface size } \\ N & \text { bubble site density } \\ O N B & \text { onset of nucleate boiling } \\ P_{l} & \text { liquid pressure } \\ P_{s a t} & \text { saturation pressure } \\ P_{v} & \text { vapor pressure } \\ q " & \text { heat flux based on the area of target surface } \\ q_{i n} & \text { power input to heater } \\ r & \text { radius of curvature of a bubble nucleus } \\ R_{a} & \text { mean surface roughness } \\ T_{s a t} & \text { saturation temperature in the chamber }\end{array}$


$\begin{array}{ll}T_{w} & \text { surface temperature } \\ \Delta T_{w}=T_{w}-T_{\text {sat }} & \text { superheat temperature at the surface }\end{array}$

Greek Symbols

$\mu_{l} \quad$ liquid viscosity

$\rho_{l} \quad$ liquid density

$\rho_{v} \quad$ vapor density

$\phi \quad$ contact angle

$\sigma \quad$ liquid surface tension

\section{Introduction}

2 With the rapid miniaturization and high density integration of electronic components and the

3 consequent increase in power density, conventional air cooling methods or single-phase liquid

4 cooling technologies for thermal management of electronic components are becoming inadequate

5 [1]. Electric-drive vehicles of the future will have high-power electrical systems for propulsion

6 that dissipate large amounts of heat fluxes of the order of more than $100 \mathrm{~W} / \mathrm{cm}^{2}$ at temperatures

7 that need to be below $175^{\circ} \mathrm{C}$ [2]. Liquid-vapor phase-change heat transfer processes, including

8 pool boiling, gas-assisted evaporative cooling, jet impingement, and spray cooling, which exploit

9 the latent heat of the cooling liquids to reduce the mass flow rates, promise to meet the

10 increasingly stringent thermal management requirements of power electronics. Due to the

11 relative simplicity of implementation, it is desirable to obtain high heat transfer coefficients $(h)$

12 and critical heat flux (CHF) with immersion pool boiling, without the use of forced convective

13 methods [1]. Surface modification techniques have been used over the past few decades to

14 enhance heat transfer performance by providing larger surface area, higher density of nucleation

15 sites, and potentially smaller superheat for the phase change heat transfer [3]. Honda and Wei [4]

16 reviewed the effect of several forms of microstructured surfaces, including laser-drilled cavities,

17 reentrant cavities, microfins, porous coatings, and sputtered surfaces. Specifically, microporous 
1 surfaces fabricated by electrolytic deposition, flame spraying, sintering, or brazing of particles,

2 have been quite extensively studied in the past for enhancing pool boiling heat transfer [5-8].

3 The heat transfer is likely enhanced due to a combination of the following factors: (i) an increase

4 in the effective surface area that leads to enhanced interaction of the liquid with the surface, (ii)

5 an increase in the nucleation site density and embryonic bubbles that grow at low superheat, (iii)

6 the presence of capillaries that facilitate liquid return to dry spots, and (iv) an increase in the

7 solid-liquid-vapor contact line length throughout the pores. Although boiling heat transfer

8 enhancement with microporous coatings is well documented, the physical mechanisms

9 responsible for the enhancements are not fully understood, which hinders the design and

10 deployment of such structured surfaces. Bergles and Chyu [9] studied pool boiling on a

11 commercially available porous coating (Linde High Flux) that consisted of micron-sized copper

12 particles brazed onto a cylindrical copper heated surface, with a diameter of $2.5 \mathrm{~cm}$ and a length

13 of $15 \mathrm{~cm}$. The porous coating with a thickness of $0.38 \mathrm{~mm}$ was found to increase boiling heat

14 transfer coefficients by as much as $800 \%$ and $250 \%$ for R-113 and water, respectively. They

15 hypothesized the enhancement is due to that nucleation occurring within cavities (inside the

16 porous layer) that are not flooded by the liquid. The resulting vapor then exits through preferred

17 escape channels, and the rewetting liquid is then supplied through other interconnected channels

18 within the porous matrix. Chang and You performed pool boiling experiments [6] with FC-72 on

19 microporous organic coatings of various thicknesses, made with thermally conductive diamond

20 particles in an organic binder ("DOA" coating: 2-70 $\mu$ m synthetic diamond

21 particles/OMEGABOND 101 epoxy binder/acetone carrier). Despite the low thermal

22 conductivity $(\sim 0.95 \mathrm{~W} / \mathrm{mK})$, these coatings led to a significantly lower nucleate boiling

23 incipience superheat $(<10 \mathrm{~K})$ as compared to $\sim 30 \mathrm{~K}$ for the plain surface, and resulted in a 
1 significant increase in the heat transfer coefficient and CHF. Kim et al. [10] studied the

2 mechanism of pool boiling with FC-72 on cylindrical platinum wire with a diameter of $390 \mu \mathrm{m}$

3 using high-speed photography. The 17- $\mu$ m-thick coating was made from dielectric DOM (8-12

$4 \mu \mathrm{m}$ synthetic diamond particles/OMEGABOMD 101 epoxy binder/methyl-ethyl-ketone carrier).

5 They found that the diameter at departure of bubbles on the microporous surface was lower than

6 the plain surface. At heat fluxes below $12 \mathrm{~W} / \mathrm{cm}^{2}$, latent heat contribution was enhanced on the

7 microporous surface, due to activation of dormant nucleation sites. At high heat fluxes,

8 convection heat transfer became larger than latent heat, possibly due to the decrease in the

9 superheated liquid layer at the surface, which inhibits latent heat transfer. Thiagarajan et al. [11,

10 12] studied pool boiling and spray impingement boiling on a vertically oriented $10-\mathrm{mm} \times 10-\mathrm{mm}$

11 copper surface coated with a $100-\mu \mathrm{m}$-thick microporous layer (similar to the one used in the

12 current work). They found that the pool boiling heat transfer coefficient was enhanced by $500 \%$

13 on the microporous surface compared to the plain surface [10]. With spray impingement, the

14 heat transfer coefficient was enhanced by $300 \%$ to $600 \%$ and the CHF was enhanced by up to

$1580 \%$ over the plain surface [11].

16 In general, it is found that heat transfer occurs through the following modes during saturated

17 nucleate boiling on a plain surface, as illustrated in Fig. 1 (a): (i) evaporation, where vapor is

18 formed by the evaporation of the thin microlayer of liquid under a growing bubble and/or of the

19 superheated liquid on the bubble wall [13, 14]; (ii) quenching [15, 16]where, after the departure

20 of a bubble, heat transfer to the cooler liquid that rushes in to fill the void occurs by transient

21 conduction; (iii) microconvection [17-19], where the agitation of the liquid by the bubble motion

22 results in increased heat convection; and (iv) natural convection, at locations on the target surface

23 far away from the bubble activity. In a relatively simple model, the following bubble nucleation 
1 quantities are usually considered in developing theoretical models to analyze heat transfer

2 characteristics: average bubble departure diameter $(D)$, average bubble departure frequency $(f)$,

3 and average active nucleation site density $(N)$. Other researchers have utilized high-speed

4 visualization in order to characterize bubble dynamics on plain surfaces and determine the

5 contributions of the phase-change and single-phase convective heat ([20-22], for example).

6 On a surface with a porous coating, heat transfer can be enhanced due to the presence of a

7 few additional modes within the passageways [3], as illustrated in Fig. 1 (b).Vapor is generated

8 by nucleation and bubble growth within the porous layer, evaporation of liquid thin-film on the

9 internal surfaces, and capillary evaporation at the menisci. Single-phase convective heat transfer

10 takes place from the particles to the liquid due to bubble pumping and vapor motion. Little data

11 exist in the literature that detail the characteristics of bubble dynamics on microporous surfaces,

12 and there appears to be none that relates the bubble characteristics to the heat transfer on a

13 microporous surface except [10].

14 Assuming condensation of vapor does not occur anywhere from the point of generation of the

15 vapor bubble until its departure from the exterior of the microporous layer, the total heat transfer

16 from the target surface to the fluid by phase-change may be estimated using the rate of vapor

17 departure from the surface. However, the single-phase heat transfer modes within the layer

18 cannot be captured in a visualization study. The objectives of this study are therefore to

19 investigate the saturated pool boiling heat transfer performance and bubble dynamics on the

20 thermally conductive microporous copper coated surface with HFE-7100 and to quantify the

21 contributions to heat transfer through different modes using high-speed visualized bubble

22 dynamics information. In the present study, the average bubble departure diameter $(D)$, the

23 average bubble departure frequency $(f)$, and the average active nucleation site density $(N)$, are 
1 calculated from high-speed movies of saturated pool boiling on plain copper surfaces of two

2 different roughness levels and on three microporous copper surfaces at different heat fluxes (in

3 the isolated bubble regime). These parameters are then used to obtain a quantitative measure of

4 the contributions due to various modes of heat transfer on the surfaces using the partition model.

\section{$5 \quad 2$ Experimental apparatus and procedure}

\section{$6 \quad 2.1 \quad$ Pool boiling setup}

$7 \quad$ The experimental setup was designed to study pool boiling heat transfer in a horizontal

8 configuration with plain or microporous copper surfaces. Because of the desirable properties of

9 the fluid HFE-7100 (very low global warming potential, zero ozone depletion potential,

10 nonflammability, high dielectric strength, and good thermophysical properties), it has been

11 identified as a potential coolant for power electronics in electric-drive vehicles [23].

12 Fig. 2 shows the schematic diagram and photograph of the setup. The setup primarily

13 consisted of an aluminum chamber to hold the test fluid (liquid-vapor) at saturation conditions,

14 and the heater and temperature sensor assembly that contained the target surface (plain or with

15 microporous coating) to be tested. The aluminum boiling chamber with a diameter of $12 \mathrm{~cm}$ and

16 a width of $5 \mathrm{~cm}$ had glass windows in the front and the back to allow for the observation of

17 boiling phenomena on the target surface. The chamber was filled with HFE-7100 liquid up to a

18 height of about $6 \mathrm{~cm}$ above the target surface. Flexible silicone heaters were attached to the

19 aluminum walls of the chamber to heat the liquid/vapor to maintain the liquid at the saturation

20 temperature. The vapor would rise to the top region of the chamber by buoyancy, go through the

21 reflux condenser located at the top of the chamber, and condense back to liquid pool. The pure

22 liquid-vapor mixture in the chamber was maintained at $54 \pm 0.2^{\circ} \mathrm{C}$, which is the saturation

23 temperature corresponding to the atmospheric pressure of HFE-7100 in Golden, Colorado (80 
$1 \mathrm{kPa}$ at an elevation of $1,730 \mathrm{~m}$ ). Table 1 gives the thermophysical properties of HFE-7100 at

2 various temperatures [24].

3 The inset in Fig. 2 (b) shows a photograph of the heater and temperature sensor assembly.

4 The assembly consisted of a cuboidal oxygen-free copper block (dimensions $2 \mathrm{~mm}$ x $10 \mathrm{~mm}$ x 30

$5 \mathrm{~mm}$, thermal conductivity $k=393 \mathrm{~W} / \mathrm{m}-\mathrm{K}$ [25]) with a beryllium oxide ceramic, thick film

6 heater with a resistance of $20 \Omega$ (Component General CCT-375) epoxied to it using a thin layer

7 of a relatively high thermal conductivity $(k=1.6 \mathrm{~W} / \mathrm{m}-\mathrm{K})$ compound (EPO-TEK EE129-4 from

8 Epoxy Technology). Two K-type thermocouples with a junction diameter of $0.25 \mathrm{~mm}$ were

9 epoxied to 0.3 -mm-diameter holes in the copper block, at distances of $1 \mathrm{~mm}$ and $4 \mathrm{~mm}$ from the

10 target surface using Arctic Silver thermal adhesive, such that the thermocouple junctions were

11 located at the center of the copper block at a position $1 \mathrm{~mm}$ from the vertical surface. This

12 copper-heater-thermocouple assembly was then placed in the cavity of a custom-fabricated

13 Teflon block $(k=0.2 \mathrm{~W} / \mathrm{m}-\mathrm{K})$ with $3 \mathrm{M}$ Scotch-Weld DP420 epoxy $(k=0.18 \mathrm{~W} / \mathrm{m}-\mathrm{K})$ filling up

14 the empty volume, so that only the 2-mm x 10-mm target surface of the copper block (along with

15 the surrounding epoxy) was exposed to the boiling chamber when assembled. The perimeter of

16 the copper surface was covered by the epoxy to prevent boiling at the edges. The heater and

17 temperature sensor assembly was placed under a circular slot in the aluminum chamber and

18 fastened tightly to the chamber to prevent any liquid leakage.

19 High-speed videos of the boiling dynamics, that is, bubble formation and departure from the

20 target surfaces, were obtained using a visualization setup that consisted of a high-speed camera

21 (Photron FASTCAM SA3 with frame rates of 1,500-3,800 fps) fitted with a long-distance

22 microscopic lens (Infinity K2S/C with CF-2 objective lens) and a cold light emitting diode

23 (LED) light source (SugarCUBE quad LED). The camera is placed at an angle of $30^{\circ}$ relative to 
1 the horizontal target surface. The target copper surface that was exposed to the liquid in the

2 chamber was rectangular with a width of $2 \mathrm{~mm}$ and length of $10 \mathrm{~mm}$. The width of the surface

3 was kept small so that the nucleation sites on the entire surface were visible during boiling in

4 order to accurately determine the bubble site density. The inputs from the thermocouples were

5 fed into a data acquisition system and read using LabVIEW, while the power supply to the target

6 heater was manually operated. The power levels were incremented by 0.1 to $0.4 \mathrm{~W}$ at heat flux

7 levels below $10 \mathrm{~W} / \mathrm{cm}^{2}$ and by $0.5-1 \mathrm{~W}$ at higher heat flux levels. To verify that the pool boiling

8 setup built for high-speed visualization on these target surfaces could be used to obtain reliable

9 data, a few tests were also conducted using a $10 \mathrm{~mm}$ (width) x $10 \mathrm{~mm}$ (length) x $2 \mathrm{~mm}$ (depth)

10 copper block in a setup similar to that used by El-Genk and Bostanci [26]. As discussed in

11 Section 3.1.1, the pool boiling curves in this study were found to agree well with the results in

12 [26] for the plain surface, thus validating the current setup.

\section{$13 \quad 2.2 \quad$ Sample surfaces}

14 Two types of surfaces were studied: the baseline case of plain copper surfaces with no

15 coating and surfaces with microporous copper coatings. The plain surfaces were prepared by

16 polishing the surfaces with \#600 grit paper, and then with \#2000 or \#1500 grit paper, resulting in

17 mean surface roughness, $R_{a}$, of $0.33 \mu \mathrm{m}$ and $0.78 \mu \mathrm{m}$, respectively, measured with a Fowler

18 Pocket Surf roughness profilometer. The surface was deoxidized before testing by wiping with

19 cotton swabs dipped in hydrochloric acid and cleaning with isopropanol. The scanning electron

20 microscope (SEM) images of the plain surfaces are shown in Fig. 3 (a) and (b). The SEM images

21 show that the cavities in the plain surfaces are of dimensions less than $1 \mu \mathrm{m}$ in diameter, and the

22 surface with $R_{a}=0.33 \mu \mathrm{m}$ is much smoother than the one with $R_{a}=0.78 \mu \mathrm{m}$. The surfaces with

23 the microporous copper coating were obtained from 3M Company. The procedure for fabricating 
1 the microporous copper layer on the plain copper surface involved fusing of copper-rich

2 microparticles of diameters between $5 \mu \mathrm{m}$ and $20 \mu \mathrm{m}$ on the copper surface at a temperature of

$3 \sim 850^{\circ} \mathrm{C}[27,28]$. Three samples with coating thicknesses of $100( \pm 8) \mu \mathrm{m}, 360( \pm 30) \mu \mathrm{m}$, and 700

$4( \pm 30) \mu \mathrm{m}$ were prepared. The porosity of the microporous coating, calculated using weight and

5 volume measurements, is found to be 55\% to 60\%. SEM images of the microporous coating,

6 shown in Fig. 3 (c) and (d), show a microstructure with irregular, elongated pore structures, with

7 cavity sizes in the range of $0.5 \mu \mathrm{m}$ to $5 \mu \mathrm{m}$, which could potentially serve as nucleation sites. The

8 presence of the microscale channels also results in a much larger surface area (compared to the

9 nominal external surface area) that is available for thin film evaporation of the liquid, which

10 could potentially augment the heat transfer. Furthermore, the network of interconnected channels

11 that facilitate liquid replenishment could potentially delay dry-out on the surface to higher heat

12 flux values as compared to the plain surface.

\section{$13 \quad 2.3 \quad$ Experimental procedure and data reduction}

14 Before each experiment, the HFE-7100 liquid in the pool boiling chamber was degassed for

1560 to 80 minutes to expel any dissolved non-condensable gases. This was accomplished by

16 boiling the liquid vigorously at $54^{\circ} \mathrm{C}$ using the guarded silicone heaters around the chamber, and

17 allowing the vapor mixed with the non-condensable gases to flow through a condenser located

18 above the chamber. The portion of the condensed vapor dripped back into the chamber, while the

19 non-condensable gases escaped. After this procedure, the system was allowed to reach a steady

20 state, with no power input to the target copper surface, so that saturation conditions existed

21 within the chamber. Then the power to the target surface was incrementally increased and

22 measurements were taken after the temperatures reached a steady state (that is, when the

23 temperature variation was $<0.05^{\circ} \mathrm{C}$ over a period of 120 seconds). The thermocouple readings 
1 were averaged over a period of 30 seconds. Assuming one-dimensional heat conduction in the

2 copper block, the heat flux through the surface $\left(q^{\prime \prime}\right)$ was determined by the temperature

3 difference across these two thermocouples using Eq. (1),

$$
q^{\prime \prime}=k \frac{\left(T_{1}-T_{2}\right)}{l_{12}},
$$

4 where $k$ is the thermal conductivity of oxygen-free copper, $T_{1}$ and $T_{2}$ are the temperatures farther

5 away and closer to the target surface, respectively, and $l_{12}$ is the distance between the

6 thermocouple locations. The calculated heat flux was then used to determine the wall

7 temperature of the target surface $T_{w}$ by assuming one-dimensional heat flow using Eq. (2),

$$
T_{w}=T_{1}-\frac{l_{1 w} q^{\prime \prime}}{k},
$$

8 where $l_{l w}$ is the distance between the thermocouple location and the surface. The heat transfer

9 coefficient, $h$, was calculated using Eq. (3):

$$
h=\frac{q^{\prime \prime}}{\left(T_{w}-T_{s a t}\right)} .
$$

10 CHF was defined as the highest heat flux at which stable target surface temperature was

11 maintained, before a sharp increase in temperature occurred $\left(>10^{\circ} \mathrm{C}\right.$ per second) with a slight

12 increase in the power input.

\section{$13 \quad 2.4 \quad$ Experimental uncertainties}

14 The uncertainty of the measured heat flux was mainly from the accuracy of the position and

15 calibration of the thermocouples. A National Institute of Standards and Technology (NIST)-

16 traceable resistance temperature detector (RTD) was used along with a Hart Scientific micro

17 calibration thermal bath model 7102 to calibrate all the thermocouples in the temperature range

18 from $20^{\circ} \mathrm{C}$ to $105^{\circ} \mathrm{C}$. The uncertainty in the temperature measurement was within $\pm 0.05^{\circ} \mathrm{C}$. The

19 uncertainty in the position of the centers of the thermocouples was estimated to be $\pm 0.05 \mathrm{~mm}$ for 
1 a $0.25-\mathrm{mm}$ thermocouple bead placed in a $0.30-\mathrm{mm}$-diameter hole. The uncertainties in voltage

2 and current were negligible $(< \pm 0.12 \%$ and $< \pm 0.05 \%$, respectively). The uncertainty in the heat

3 flux measurement was estimated using the Kline and McClintock method [29] to be $\pm 10 \%$ at

4 heat fluxes below $5 \mathrm{~W} / \mathrm{cm}^{2}, \pm 6 \%$ at heat fluxes above $8 \mathrm{~W} / \mathrm{cm}^{2}$, and in the intermediate range,

5 between $\pm 6 \%$ and $10 \%$.

6 Finite element analysis of heat conduction was conducted on the test article to quantify

7 thermal losses and to ensure that the heat flux could be reliably calculated using the two

8 thermocouples, as shown in Fig. 4. A three-dimensional computer-aided design model of the test

9 article was created and imported into ANSYS Workbench for a steady-state heat transfer

10 simulation. The analysis was performed for multiple heat input levels, assuming a uniform heat

11 transfer coefficient on the target surface, and a set of heat transfer coefficients for the different

12 modes of heat loss. The heat loss modes included natural convection to the air surrounding the

13 Teflon block, convective heat transfer to the liquid from the epoxy, and Teflon surrounding

14 heated copper block.

15 Fig. 4 shows the results of the simulation for two cases of input heat of $1.74 \mathrm{~W}$ and 5.83

16 W, with experimentally calculated pool boiling heat transfer coefficients, as shown in Eq. (3), of

$174,200 \mathrm{~W} / \mathrm{m}^{2}-\mathrm{K}$ and $13,200 \mathrm{~W} / \mathrm{m}^{2}-\mathrm{K}$, respectively. The boundary conditions are show in Fig. 4 (a).

18 In the model, the input values were the power input $\left(q_{i n}=V \cdot I\right.$, where $V$ is the voltage and $I$ is the

19 current through the cartridge heaters), the pool boiling heat transfer coefficient, and the loss heat

20 transfer coefficients. The set of coefficients for heat loss was obtained by iteratively trying

21 different values until the temperatures obtained in the ANSYS model (and heat flux from the

22 surface) matched the corresponding experimental values. The heat transfer through the different

23 surfaces (including the copper target surface) and the temperatures at all points were the outputs. 
1 Fig. 4 (b) shows the temperature of the copper block along the direction of heat flow. Fig. 4 (c)

2 and (d) show the temperature contours in the planes where the thermocouples are placed in the

3 copper block ( $T_{1}$ and $T_{2}$, respectively). In both cases, the temperature in each plane is uniform

4 within $0.05^{\circ} \mathrm{C}$ in both planes, and the average calculated temperature is within $\pm 0.05^{\circ} \mathrm{C}$ of the

5 measured values. This confirmed that the pool boiling heat flux and surface temperature could be

6 calculated using the temperatures measured by the two thermocouples.

\section{$\begin{array}{lll}7 & 3 & \text { Results and discussion }\end{array}$}

\section{$8 \quad 3.1 \quad$ Experimental boiling curves}

\section{$9 \quad$ 3.1.1 Measurements on 10-mm x 10-mm surfaces}

10 To verify that the pool boiling setup with visualization capability designed in this work could be

11 used to obtain reliable data, a few tests were conducted using a 10-mm (width) x 10-mm (length)

12 x 2-mm (depth) copper block in a setup similar to that used by El-Genk and Bostanci [26].

13 Saturated pool boiling heat transfer data of HFE-7100 by El-Genk and Bostanci [26] on a 10-mm

14 x 10-mm plain copper surface that was sanded with a \#1500 grit paper is shown in Fig. 5. In the

15 comparison tests, only one thermocouple was placed at $1 \mathrm{~mm}$ below the surface to estimate the

16 surface temperature. The heat flux through the surface was assumed to be equal to the $q_{\text {in }}(=V \cdot I)$.

17 As the design of this heater assembly is similar to [26] and [30], where simulations showed that

18 the heat loss was below $2 \%$, the losses in the current work are also assumed to be small, and

19 therefore neglected.

20 The surface was polished using \#1500 and \#2000 grit paper resulting in roughness of

$210.78 \mu \mathrm{m}$ and $0.33 \mu \mathrm{m}$, respectively. As expected, Fig. 5 shows that the onset of nucleate boiling

22 (ONB) occurs at a higher superheat on the smoother sample $\left(R_{a}=0.33 \mu \mathrm{m}\right)$ than that on the

23 rougher sample $\left(R_{a}=0.78 \mu \mathrm{m}\right)$. A lower heat transfer coefficient is observed on the smoother 
1 surface, as evidenced from the higher surface superheat temperature at the same heat flux. The

2 variation of the CHF due to the level of surface roughness was found to be within experimental

3 uncertainties [31]. A repeated measurement on the $0.78-\mu \mathrm{m}$ surface after a period of 44 hours of

4 idle waiting (with the surface in contact with the liquid maintained at $20^{\circ} \mathrm{C}$ after one cycle of

5 measurement), showed that the $\mathrm{ONB}$ increased to $17^{\circ} \mathrm{C}$ as compared to $11^{\circ} \mathrm{C}$ in the first

6 measurement on the surface. This indicates that the highly wetting nature of HFE-7100 results in

7 flooding and deactivation of larger cavities, and thus the size of the nucleating vapor embryo

8 changes over time despite the cavities' geometry remaining intact [31]. However, the changes in

9 the heat transfer coefficient and the CHF are found to be negligible.

10 Based on the hydrodynamic instability model, the CHF on an infinitely large plain

11 surface [32] is computed using the Lienhard-Dhir correlation, which gives a value of $16.7 \mathrm{~W} / \mathrm{cm}^{2}$

12 for HFE-7100. In our measurements, the $10-\mathrm{mm} \times 10-\mathrm{mm}$ samples gave a slightly higher value

13 of $\sim 18.5 \pm 1.1 \mathrm{~W} / \mathrm{cm}^{2}$. Interestingly, the pool boiling curve corresponding to the surface polished

14 with \#2000 grit paper agreed closely with the data corresponding to the surface polished using

$15 \# 1500$ grit paper in [26]. However, the CHF that we obtained was significantly lower than 25

$16 \mathrm{~W} / \mathrm{cm}^{2}$ as reported in [26]. Overall, we consider our measurement on the $10-\mathrm{mm} \times 10-\mathrm{mm}$

17 surface to be in good agreement with the literature. In Fig. 5, the pool boiling curve on a 2-mm x

18 10-mm target surface is also shown, which is also found to be in the same range as the larger

19 surface in the nucleate boiling regime, while the CHF is enhanced as expected for the smaller

20 target surface, consistent with [33].

\section{$21 \quad 3.1 .2$ Measurements on 2-mm x 10-mm surfaces}

22 Visualization of the bubble dynamics on the target surface requires unobstructed view of

23 all the bubble sites to accurately measure the site density, diameter, and frequency of departure. 
1 As the depth-of-focus of the lens is limited to about $2 \mathrm{~mm}$, the width of the target surface was

2 kept at $2 \mathrm{~mm}$. However, if the target surface size is too small, boiling on the surface may become

3 dominated by the surface tension effects rather than buoyancy, making the data unrepresentative

4 of boiling on larger surfaces. By studying pool boiling data on target surfaces of different sizes

5 under various acceleration-due-to-gravity levels, Raj and Kim [34] determined that when the size

6 of the target surface $L_{h}>2.1 L_{c}$, where $L_{c}=\left[\sigma /\left(g\left(\rho_{l}-\rho_{v}\right)\right)\right]^{1 / 2}$ is the capillary length, the

7 boiling process is dominated by buoyancy rather than surface tension. At $T_{s a t}=54^{\circ} \mathrm{C}$, the

8 capillary length of HFE-7100 is $0.85 \mathrm{~mm}$. The boiling characteristics on the 2-mm x 10-mm

9 target surface is considered to be representative of larger boiling surfaces, because it satisfies the

10 criterion $L_{h}=2 \mathrm{~mm}>2.1 L_{c}$.

11 Fig. 6 (a) shows the boiling curves obtained for the five surfaces with the surface area $2 \mathrm{~mm}$

$12 \mathrm{x} 10 \mathrm{~mm}$ exposed to the liquid: two plain surfaces with different roughness $\left(R_{a}=0.33 \mu \mathrm{m}\right.$ and $R_{a}$

$13=0.78 \mu \mathrm{m}$ ) and three microporous copper surfaces with different thickness of coatings (with 100-

$14 \mu \mathrm{m}, 360-\mu \mathrm{m}$, and $700-\mu \mathrm{m}$-thick layers). As expected, the ONB, $h$, and CHF all differ with each

15 other depending on the surface condition of these samples. As the heater power level is raised

16 from zero, and the surface temperature is increased from the saturation temperature

17 (corresponding to $\Delta T_{w}=T_{w}-T_{s a t}=0$ ), nucleate boiling on the surface does not start until the

18 "onset" happens. The ONB results in a sudden reduction in the surface temperature, a

19 phenomenon called "incipience temperature drop," which could result in damage to the device

20 due to thermal shock [1]. This is particularly pronounced in highly wetting dielectric fluids such

21 as HFE-7100, as they tend to flood even sub-micron cavities and deactivate them. Also, a large

22 incipience superheat temperature can result in the temperature of the device exceeding the safe

23 operating limit. Therefore, the incipience overshoot needs to be eliminated or minimized to 
1 increase device life and reliability. In the Fig. 6 (a), the ONB for the two plain surfaces is as high

2 as $17^{\circ} \mathrm{C}-38^{\circ} \mathrm{C}$. The difference in the $\mathrm{ONB}$ is due to the difference in the surface roughness (see

3 Fig. 4) and the resultant variation of the size of the cavities that allow for initiation of bubble

4 nucleation. In comparison, the ONB superheat on the microporous surfaces occurs at

5 temperatures below $11^{\circ} \mathrm{C}$, which would be much more favorable for use in electronics cooling.

6 Repeated measurements showed that the ONB superheat varies by as much as $\pm 7^{\circ} \mathrm{C}$ on the plain

7 surfaces. The variation between the first and subsequent measurements on a given surface is

8 likely due to the random manner in which cavities of various sizes are activated resulting in

9 nucleation, and/or due to the flooding of some cavities in the reworked surface which results in

10 no embryo for nucleation [35]. The ONB superheat is much more repeatable on the microporous

11 surface, with only $\pm 3^{\circ} \mathrm{C}$ variation.

12 The Laplace-Young equation describes the pressure difference across the surface of a vapor

13 bubble, $P_{v}-P_{l}=2 \sigma / r$, where $P_{v}$ is the vapor pressure, $P_{l}$ is the liquid pressure, $r$ is radius of

14 curvature of the bubble and $\sigma$ is the surface tension. Along with the Clausius-Clapeyron relation,

15 the Young-Laplace equation is used to estimate the critical diameter at bubble nucleation from

16 the ONB [35], resulting in the equation:

$$
D_{c r i t, C C}=\frac{4 \sigma T_{s a t}}{\rho_{v} h_{l v} \Delta T_{w, O N B}},
$$

17 where $\sigma$ is the liquid surface tension, $T_{s a t}$ is the saturation temperature, $\rho_{v}$ is the vapor density, $h_{l v}$

18 is the latent heat of vaporization, and $\Delta T_{w} O N B$ is the wall superheat at the ONB. The critical

19 diameter is an estimation of the diameter of the cavity where a vapor nucleus can grow into a

20 bubble without condensing, at a given wall superheat. The prediction given by Eq. (4) is

21 appropriate when the contact angle is large $\left(\phi \sim 90^{\circ}\right)$, the incipience superheat is small, and the

22 saturation curve is nearly linear over the range from the saturation temperature of the liquid to 
1 the temperature of the superheated vapor within the bubble [36]. However, for a highly wetting

2 liquid, the incipience superheat at ONB can be large, and thus the relation between $T_{\text {sat }}$ and $P_{\text {sat }}$

3 would be nonlinear, thereby invalidating the use of the Clausius-Clapeyron relation, and hence

4 Eq. (4). An equivalent expression that takes into account the nonlinearity is given by the

5 following equation [36]:

$$
\Delta T_{w, O N B}=T_{w, O N B}-T_{\text {sat }}\left(\text { at } P_{l}\right) \cong T_{\text {sat }}\left(P_{l}+\frac{4 \sigma\left(\text { at } T_{w, O N B}\right)}{D_{\text {crit }}}\right)-T_{\text {sat }}\left(\text { at } P_{l}\right) .
$$

6 The relation between $T_{\text {sat }}$ and $P_{\text {sat }}$ for HFE-7100 [24] is given by:

$$
\ln (P[\text { pascal }])=\frac{-3641.9}{T[\text { kelvin }]}+22.415 \text {. }
$$

7 The critical diameters of the nucleating cavity computed using the minimum and maximum

8 values of $\Delta T_{w}$ ONB from Eqs. (5) and (6) for the various surfaces are shown in Table 2. The data

9 show that the microporous surface contains cavities $>1 \mu \mathrm{m}$ that can get activated at low

10 superheats, resulting in onset of nucleation much before the plain surface. Fig. 7 shows the

11 critical diameters for the various surfaces plotted as a function of the surface superheat, overlaid

12 on a plot of the size range of active nucleation sites calculated using Hsu's criterion [37] for a

13 variety of contact angles. The fact that many of the measured data points lie outside the curves

14 corresponding to $\phi \leq 7.5^{\circ}$ suggests that the relevant contact angle of liquid-vapor interface is

15 higher than the static contact angle $\left(<1^{\circ}\right)$.

Fig. 6 (a) also shows that the CHF on the microporous surface is enhanced by about

$1733 \%-60 \%$ as compared to that on the plain surfaces. Though the difference is small, the CHF

18 decreases monotonically with an increase in the microporous layer thickness. This is likely due

19 to the choking of the liquid pathways occurring at a relatively lower heat flux level in the thicker

20 layer. 
Fig. 6 (b) shows the heat transfer coefficient as a function for the heat flux. The $h$ is

2 enhanced by $50 \%$ to $270 \%$ on the microporous surfaces over the plain surfaces. The $h$ on the

$3 \quad 700-\mu \mathrm{m}$ microporous sample is the highest of all in the isolated bubbles and fully developed

4 nucleate boiling regimes. The $h$ in this regime increases with the increasing thickness of the

5 layer. This is probably due to the presence of a larger number of nucleating sites within the

6 thicker layer, resulting in more intensive phase-change heat transfer. At wall superheat $>15^{\circ} \mathrm{C}$

7 (corresponding to heat flux $>20$ to $25 \mathrm{~W} / \mathrm{cm}^{2}$ ) the slopes of the boiling curves, as shown in Fig. 6

8 (a), of the microporous surfaces start to decrease, resulting in the reduction in the $h$ after reaching

9 the peak value. At high heat fluxes, the increased rate of vapor generation and motion from

10 within the layer to the outside leads to the decrease in the pathways available for liquid reflow,

11 which leads to a decrease in the heat transfer coefficient.

\section{$12 \quad 3.2$ Bubble dynamics}

13 High-speed visualization offers the possibility of obtaining detailed and temporally resolved

14 information on the dynamics of bubbles growth and departure from the target surface at a high

15 magnification level $(25 \mathrm{x}-30 \mathrm{x})$. In the following sections, we will discuss the bubble dynamics on

16 various surfaces as measured using high-speed video. The Photron FASTCAM Viewer program

17 was used for the measurement of the various parameters. Visualization measurements were used

18 to obtain the bubble characteristics up to a heat flux (and surface superheat) value that allowed

19 for discerning individual bubbles. The crowding of the bubbles on the surface and their

20 coalescence make measurements beyond this heat flux $\left(\sim 10 \mathrm{~W} / \mathrm{cm}^{2}\right)$ difficult and not reliable.

21 Fig. 8 shows representative images of bubble dynamics on plain and microporous surfaces at

22 various heat flux levels.

\section{$23 \quad$ 3.2.1 Bubble site density}


Each video file was analyzed to determine the locations of the active nucleation sites on the

2 test surface. The instantaneous number of active sites captured by a still frame was generally not

3 as high as the total, cumulative number of sites that were active at least once over several

4 departure periods [38]. The cumulative number of sites was determined by counting all the sites

5 that were active over any part of an arbitrarily selected 100 frames that represented several

6 bubble cycles. The area density of active nucleation sites, $N$, was then calculated by dividing the

7 counted number of active sites by the area of the surface. The uncertainty in the measurement is

8 estimated to be $10 \%$ for low heat fluxes and up to $20 \%$ for high heat fluxes where the field of

9 view was frequently obstructed, by repeatedly counting the number of active sites on successive

10 sets of 100 frames each. The number of active sites increased with increasing wall superheat and

11 with increasing surface roughness for the plain surface. Incipience of nucleate boiling on the

12 microporous surface occurred at a much lower temperature; and consequently, the bubble site

13 density in the microporous surface was many times higher than that of the plain surface at any

14 given superheat. Fig. 9 and Fig. 10 show the nucleation site density as a function of the wall

15 superheat on the plain and microporous surfaces, respectively. Since nucleation in the

16 microporous surface takes place within the layer, the visual image only gives us the number of

17 sites of bubble release from the surface. Hence, site density is referred to as "bubble site density"

18 to be more general. As expected, the plain surface with the higher roughness level produced

19 more bubbles than the smoother plain surface. In regard to the microporous surfaces, the bubble

20 site density was observed to increase strongly with the increasing temperature. However, no clear

21 pattern in terms of the site density versus the layer thickness could be discerned.

22 The bubble site density on the plain surfaces were compared with models developed by

23 Hibiki-Ishii (H-I) [39], Kocamustafaogullari-Ishii (K-I) [40], and Benjamin-Balakrishnan (B-B) 
1 [41] models. The H-I correlation was developed by fitting to a wide array of experimental

2 nucleation site density data for boiling on plain surfaces. They assumed that nucleating cavity

3 number and size distributions would be statistically similar for most boiling systems, accounting

4 for surface characteristics by including a static contact angle term. However, given that the static

5 contact angle of HFE- 7100 is $<1^{\circ}$, the predicted values of the site density $\left(N_{H I}\right)$ were several

6 orders of magnitude smaller than the experimentally observed values $(N)$. Very good agreement

7 was obtained if $\phi$ was assumed to be $41^{\circ}$ to $48^{\circ}$ for the plain surfaces, with only the contact angle

8 being the varying parameter. It is reasonable to assume that during a nucleate boiling process, the

9 dynamic contact angle (which tends to be much larger than the static contact angle and

10 dependent on the velocity of the liquid-vapor interface) is the relevant parameter [42], instead of

11 the static contact angle. This is reinforced by the observation that active nucleation cavity sizes

12 lie outside of the size range given by Hsu's criterion with a contact angle of $<7.5^{\circ}$, as discussed

13 in section 3.1.2. The H-I correlation is given by the following set of equations:

$$
\begin{gathered}
N_{H I}=N_{n}\left\{1-\exp \left(-\frac{\phi^{2}}{8 \mu^{2}}\right)\right\}\left[\exp \left\{f\left(\rho^{+}\right) \frac{\lambda^{\prime}}{R_{c}}\right\}-1\right] \\
R_{c}=\frac{2 \sigma\left\{1+\left(\rho_{v} / \rho_{l}\right)\right\} / P_{l}}{\exp \left\{h_{l v}\left(T_{w}-T_{s a t}\right) /\left(R T_{w} T_{\text {sat }}\right)\right\}-1} \\
f\left(\rho^{+}\right)=-0.01064+0.48246 \rho^{+}-0.22712 \rho^{+^{2}}+0.05468 \rho^{+^{3}} \\
\rho^{+}=\log _{10}\left(\frac{\rho_{l}-\rho_{v}}{\rho_{v}}\right),
\end{gathered}
$$

14 where $N_{n}=4.72 \times 10^{5}$ sites $/ \mathrm{m}^{2}, \mu=0.722 \mathrm{rad}$, and $\lambda^{\prime}=2.5 \times 10^{-6} \mathrm{~m} . R$ is the gas constant based 15 on the molecular weight. For HFE-7100, $R=33.24 \mathrm{~J} /(\mathrm{kg}-\mathrm{K})$.

16 For the three microporous surfaces, the contact angle is kept constant at $\phi=46^{\circ}$ and only $N_{n}$

17 is varied to obtain good fits to the experimental data. The $N_{n}$ in the H-I correlation is a coefficient

18 that is related to the average cavity density on (smooth) surfaces. Therefore, it is reasonable to 
1 assume that this could be the parameter that varies in the microporous surfaces depending on the

2 thickness.

3 The K-I model assumes that the nucleation site density and the critical cavity radius can be

4 normalized by the length scale of the bubble departure diameter. Using the departure diameter

5 experimentally obtained (rather than use the Fritz correlation as recommended), reasonably good

6 agreement was obtained for the plain surfaces (Fig. 9), while it severely underpredicted the $N$ on

7 the microporous surfaces. The B-B model only takes into account the average surface roughness

8 and also was found to underpredict the observed $N$ by more than one order of magnitude. Fig. 11

9 shows the experimentally measured $N$ along with the predictions based on the H-I correlation for

10 all the surfaces. The bubble site density is assumed to increase with the superheat temperature up

11 to a value given by the condition of hexagonal close-packed bubble density on the surface,

$12 N_{\max }=2 /\left(\sqrt{3} D^{2}\right)$. After that superheat value, the bubble site density is assumed to be constant.

\section{$13 \quad$ 3.2.2 Bubble departure diameter}

14 As a bubble grows in size, buoyancy eventually becomes larger than the force that pins the

15 bubble to the surface. Using the videos, the bubble departure diameter was calculated by

16 averaging three diameter measurements immediately after the departure over a period of about

171.5 to 3 milliseconds. Based on repeated measurement of the bubbles, it was determined that the

18 diameter measurements obtained from the images have an uncertainty of $\pm 15 \%$. The uncertainty

19 is due to error in locating the bubble edges, the time-dependent non-spherical shape of the

20 bubbles, and the fact that the bubbles emanating from the same site over multiple cycles also

21 differ in size. The departure diameter also varies with the site. In all the experiments, the bubble

22 diameters varied between 0.2 to $0.8 \mathrm{~mm}$, with a majority around 0.45 to $0.6 \mathrm{~mm}$. A representative

23 distribution of the diameters on the plain and microporous surfaces is shown in Fig. 12 (a). The 
1 average bubble departure diameters for the various surfaces are shown in Fig. 12 (b). The

2 average diameter seems to be only weakly dependent on the superheat temperature on all the

3 surfaces, and decreases slightly with increasing temperature. The average diameter at departure

4 is about $0.5 \mathrm{~mm}$ on the plain surfaces. The bubble diameter at departure on the microporous

5 surface is a little higher ( $\sim 0.55$ to $0.6 \mathrm{~mm})$ than on the plain surfaces. This is probably due to the

6 fact that the bubble growth in the case of the microporous surface happens due to vapor

7 generation within the microporous layer, in addition to the growth that takes place due to

8 evaporation after the bubble comes outside of the microporous layer. Since the cavity sizes are

9 larger on the microporous layer relative to the plain surface, the surface tension force that pins

10 the bubble to the surface will also be higher, thereby allowing the bubble to grow larger than that

11 on the plain surface before departure.

12 Several correlations have been proposed in the literature to predict the bubble departure

13 diameter in pool boiling. The experimentally measured diameter are compared to correlations

14 proposed by Cole [43], Kutateladze and Gogonin [44], Jensen and Memmel [45], and Phan et al.

15 [46] in Fig. 12. Of these, the correlation by Phan et al., shown in Eq. (8), predicted the trend and

16 values of the experimental data most closely (with the contact angle $\phi=41^{\circ}$ to $48^{\circ}$, same as the

17 value used in the H-I correlation for nucleate site density). This is an empirical correlation,

18 developed with pool boiling of water on nanocoated surface resulting in the contact angle in the

19 range $20^{\circ}<\phi<110^{\circ}$ :

$$
D=0.63 \frac{\left(2+3 \cos \phi-\cos ^{3} \phi\right)}{4} L_{c}
$$

20 where $L_{c}$ is the capillary length and $\phi$ is the contact angle. At heat flux levels $q^{\prime \prime}>8$ to $10 \mathrm{~W} / \mathrm{cm}^{2}$,

21 lateral coalescence (between bubbles adjacent to each other on the surface) and vertical 
1 coalescence (between subsequent bubbles at the same site) became significant enough to render

2 the measurement impossible.

\section{$3 \quad$ 3.2.3 Bubble departure frequency}

4 The number of bubble cycles per unit time at a given cavity location is defined as the bubble 5 departure frequency. In the high-speed video files, bubbles growing at a location, within $\sim \pm 0.2$

$6 \mathrm{~mm}$, were all considered to be formed at the same nucleating cavity site. The bubble departure

7 frequency was estimated by observing the number of bubbles that departed from a given

8 nucleation site over a period of time (typically between 180 and 210 frames, corresponding to a

9 time period of about 10 milliseconds). An average of the frequency of departure at a few sites

10 (three to five) that are approximately of the same diameter at departure was taken to be the

11 average departure frequency. The uncertainty in departure frequency is estimated to be $\pm 13 \%$,

12 based on the measurements from several sets of the bubble sites. The average value of the

13 measured bubble departure frequencies are plotted with respect to the surface superheat

14 temperature in Fig. 13, along with linear fits for each surface. On all the surfaces, the bubble

15 departure frequency increases steeply with the superheat temperature. At the heat flux levels $>8$

16 to $10 \mathrm{~W} / \mathrm{cm}^{2}$, increased lateral bubble mergers made frequency measurements meaningless. In a

17 bubble growth cycle, with $t_{g}$ being the bubble growth period, and $t_{w}$ the waiting period (between

18 bubble departure and inception of a new bubble) at a given site, the frequency is essentially $f=$

$191 /\left(t_{g}+t_{w}\right)$. In the experiments, at all heat flux levels, it was found that the bubble cycles were

20 nearly continuous (that is, $t_{w} \ll t_{g}$ ). This is different from the $t_{w}>t_{g}$ observed during pool

21 boiling of water [21]. This implies that transient conduction of heat from the surface to the liquid

22 in the waiting period may not be a significant factor in our study, unlike the observation with

23 pool boiling of water in [21], where the transient conduction was found to be the dominant mode 
1 of heat transfer. Moghaddam and Kiger also observed in single-bubble pool boiling with FC-72

2 that the waiting period was often small [47].

3 For the microporous surface, once again the frequency of bubble departure does not seem to

4 be clearly dependent on the thickness of the layer, though the thickness appears to positively

5 affect the frequency. This again is probably due to the fact that the thicker layer allows higher

6 rate of vapor generation.

7 Peebles and Garber [48] developed the following correlation for the relation between the

8 frequency and bubble departure diameter, for the case where the bubble waiting time is

9 negligible:

$$
D f=1.18\left(\frac{t_{g}}{t_{g}+t_{w}}\right)\left[\frac{\sigma g\left(\rho_{l}-\rho_{v}\right)}{\rho_{l}{ }^{2}}\right]^{0.25},
$$

10 where $\sigma$ is the surface tension of the liquid, $g$ is the acceleration due to gravity, $\rho_{l}$ is the density of

11 the liquid, and $\rho_{v}$ is the density of the vapor. Because $t_{w} \ll t_{g}$, the term in the parentheses $\sim 1$.

12 For the plain surface with the $D \sim 0.5 \mathrm{~mm}$, this gives $f \sim 214 / \mathrm{s}$, which is in the observed

13 frequency range in the present study. However, because the diameter at departure is relatively

14 constant with temperature, this equation implies that the frequency also should be constant,

15 which is contrary to the measured data. The other departure frequency correlations tested [49]

16 also are not applicable to the pool boiling of HFE-7100, in magnitude and trends [50].

\section{$17 \quad 3.3 \quad$ Partition of heat flux}

18 The heat flux partition model has been commonly used for mechanistically predicting the

19 nucleate boiling heat transfer. In the model proposed by Bowring [51], the total heat transfer in a

20 boiling process is partitioned into single-phase heat and phase-change heat. The former refers to

21 the amount of heat that is transferred to the cold fluid to raise its temperature above the 
1 saturation temperature, and the latter refers to the heat going into changing the phase of the

2 liquid into vapor. The single-phase heat flux can be further subdivided into natural convection at

3 the locations on the target surface that are not nucleating bubbles, and are far enough away to be

$4 \quad$ unaffected by the churning motion of the liquid induced by the bubble motion.

5 The phase-change heat transfer is calculated from the total volume of vapor generated based

6 on bubbles from all the nucleation sites. The volume of vapor generated is estimated from the

7 vapor bubbles in the liquid just after they leave the surface. Originally developed for flow

8 boiling, it has been applied to pool boiling also. Gerardi et al. [21] applied the partition model to

9 pool boiling of deionized water and nanofluids and found that partition model was capable of

10 predicting the correct order of magnitude of the heat flux, though the difference was typically

11 large.

12 At the lower heat fluxes in the isolated-bubble regime, the following equations are used to

13 obtain the following heat flux partitions (refer to Fig. 1 (a)).

14 1. The phase-change heat flux $\left(q_{\text {evap }}\right.$ ) is calculated from the total volume of vapor

15 generated based on bubbles from all the nucleation sites:

$$
q_{\text {evap }}=\frac{\pi}{6 A} \rho_{v} h_{l v} N D^{3} f
$$

16 2. The single-phase portion of the heat transferred to the liquid is considered to be due to:

17 (1) natural convective heat transfer, $q_{\text {NatConv }}$, at locations undisturbed by the bubble 18 activity, calculated using the McAdams correlation [52], and (2) the "quenching heat

19 flux," which refers to the amount of heat transferred to the cooler fluid that rushes to the

20 surface after a bubble departs, which is the heat that is expended in the formation of a

21 new thermal boundary layer after the departure of the bubble from the previous cycle

22 [53]. The quenching heat flux $\left(q_{\text {quench }}^{\prime \prime}\right)$ is a transient heat conduction process and is 
modeled by the heat conducted to a semi-infinite layer of fluid during the waiting time between bubble cycles:

$$
q_{\text {quench }}^{\prime \prime}=\frac{2 \pi k_{l} \Delta T_{w}}{\sqrt{\pi \alpha_{l}}} N D^{2} f \sqrt{t_{w}}
$$

where $k_{l}$ is the thermal conductivity of the liquid, $\alpha_{l}$ is the thermal diffusivity of the liquid, and $t_{w}$ is the waiting time period. From space- and time-resolved studies on pool boiling of a single bubble, Demiray and Kim [54] and Moghaddam and Kiger [55] observed that the transient heat conduction to the liquid happens not only during the "quenching process" during the waiting period, but also throughout the bubble growth and departure duration. Assuming gradual rewetting of the target surface by the liquid front after departure of a bubble, and for the limiting condition cases with very small waiting time, they derived the following equation for the transient conduction heat flux:

$$
q_{\text {quench }}^{\prime \prime}=2.15 \frac{k_{l}\left(0.65 \Delta T_{w}\right)}{\sqrt{\pi \alpha_{l}}} N D^{2} \sqrt{f} \text {. }
$$

As mentioned previously, from the visualization experiments, we found that the waiting time was much smaller than the bubble growth time. Thus Eq. (12) provides a physical picture that is closer to the observation than the quenching model, Eq. (11). The total heat

flux was then computed as the sum of the three components-phase change heat flux, transient conduction heat flux, and natural convection: $q_{\text {total proj }}=q_{\text {evap }}+q_{\text {quench }}+$ $q_{N C}$. The site density, departure diameter and frequency measurements made in the isolated-bubbles regime were extrapolated to higher superheat temperatures up to the CHF using the correlations discussed previously. In addition, the site density was assumed to reach a maximum $\left(N_{\max }\right)$ corresponding to the fully-packed condition and the frequency at $f_{\max }=280 / \mathrm{s}$ after which vertical bubble coalescence became large. Bubble 
interactions and coalescence and their effect on the heat transfer are not accounted for in these models. Using these equations, the heat flux partitions for the plain and microporous coated surfaces were obtained.

\section{$4 \quad$ 3.3.1 Plain surfaces}

Fig. 14 (a) and (b) show the heat flux partition calculated from the $N, D$, and $f$ on the

6 plain surface (with $R_{a}=0.33 \mu \mathrm{m}$ and $0.78 \mu \mathrm{m}$, respectively) as a function of the superheat. The

7 solid symbols indicate the partition fluxes calculated using the experimentally obtained bubble

8 parameters. The open symbols denote the partition fluxes calculated using the projected values of $9 \quad N, D$, and $f$ from the correlations.

Based on the partition model, the proportions of heat that go into evaporative, quenching,

11 and convection modes are plotted in the figures. The natural convection mode contributes little

12 due to the small area of convection and the low natural convection heat transfer coefficient, and

13 it decreases very quickly with increasing superheat. The evaporative and quenching (transient

14 conduction) components contribute most to the total heat flux, and nearly equally (both

15 contributing about $40 \%$ to $48 \%$ of the total calculated heat flux). In their experiments on pool

16 boiling of water on plain surface, Gerardi et al. [21] observed that the quenching heat transfer

17 was the dominant mode, and evaporative and convective modes were considerably smaller

$18(<10 \%)$. This is probably because HFE-7100 is much more volatile than water, thus evaporates

19 more readily resulting in a higher amount of heat going into the phase-change process.

The total calculated heat flux from the partition model matches much better with the

21 experimental heat flux for the smoother plain surface, as shown in Fig. 14 (a), than the rougher

22 surface, as shown in Fig. 14 (b). This is likely because the bubble site density on the smoother

23 surface is much smaller than on the rougher surface, resulting in much less interference between 
1 bubble sites. Thus the partition model, which neglects the heat transfer effects of the interference,

2 is more accurate for the smooth surface. In the higher temperature range with projected values of

3 the bubble site density, the total calculated heat flux falls significantly short of the experimental

4 values. This is because the site density prediction from the H-I correlation for this surface does

5 not grow as quickly with temperature as the experimental data (Fig. 11). The quenching and

6 evaporative components follow a straight line as a function of temperature beyond $21^{\circ} \mathrm{C}$

7 (smoother surface) and $19^{\circ} \mathrm{C}$ (rougher surface), corresponding to the range where the site density

8 and frequency are assumed to be constant.

\section{$9 \quad 3.3 .2 \quad$ Microporous surfaces}

10 Fig. 15 shows the heat flux partition calculated from the $N, D$, and $f$ on the three microporous

11 surfaces as a function of the superheat. The solid symbols indicate the partition fluxes calculated

12 using the experimentally obtained bubble parameters. The open symbols denote the partition

13 fluxes calculated using the projected values of $N, D$, and $f$ from the correlations.

14 In the low temperature range with the experimentally obtained values of the bubble

15 parameters, the evaporative component is found to be the largest, followed by the quenching

16 component. The evaporative component contributes ( $65 \%$ to $73 \%$ of total calculated)

17 significantly more than the quenching component ( $20 \%$ to $25 \%)$. The natural convection

18 component is close to zero. Compared to the plain surface, the contribution of the evaporative

19 mode is much higher. This is due to the enhanced nucleation on the microporous surface versus

20 the plain surface. In the high temperature range $\left(q^{\prime \prime}\right.$ expt $\left.>25 \mathrm{~W} / \mathrm{cm}^{2}\right)$, with the heat flux

21 partitions calculated using the projected values of the bubble parameters, the slope of the total

22 experimental heat flux is found to be about the same as that of the total calculated heat flux from 
1 the partition model, with the offset being about 7 to $12 \mathrm{~W} / \mathrm{cm}^{2}$. This is possibly an indication that

2 the bubble site density is indeed constant, just as assumed in the model.

3 In the microporous surface, the nucleation of bubbles takes place in cavities within the layer.

4 The vapor bubble that is formed within the pores then moves through the pores before being

5 released into the pool, detaching from the target surface. From the visualization method, we are

6 able to observe the volume of bubble generated and therefore any heat transfer mode that results

7 in the phase-change is indirectly accounted for. However, the bubble motion through the tunnels

8 of the microporous layer will result in single-phase convective heat transfer to the liquid

9 interface between the vapor and the solid. While the quenching component $\left(q_{q u e n c h}\right)$ accounts for

10 the single-phase convection during bubble growth outside the layer, the convective single-phase

11 heat transfer within the microporous layer is not accounted for in the partition model. Taking this

12 into consideration, it seems to suggest that a portion of the total heat flux to the pool from the

13 heater with the microporous layer may actually be in the form of sensible heat transfer caused by

14 the bubble motion through the pores, in addition to the enhancement due to the effects of bubble

15 coalescence within and on the surface.

\section{Conclusions}

17 We experimentally studied the pool boiling heat transfer performance of copper surfaces

18 coated with a thermally conductive microporous copper layer, in comparison with plain surfaces

19 of two different roughness levels. Better heat transfer performances were observed with the

20 microporous surface. Under all conditions tested, the microporous surface showed lower boiling

21 incipience temperature $\left(3^{\circ} \mathrm{C}-11^{\circ} \mathrm{C}\right)$ than the plain surface $\left(17^{\circ} \mathrm{C}-38^{\circ} \mathrm{C}\right)$ due to the presence of

22 cavities in the size range of 1 to $5 \mu \mathrm{m}$ in large numbers on the microporous surface. The heat

23 transfer coefficient increased by $50 \%-270 \%$ on the microporous surface as a result of the much 
1 larger nucleate site density than on the plain surfaces. The CHF was enhanced by $33 \%$ to $60 \%$

2 for the microporous surface over the plain surface. High-speed visualization was utilized to

3 obtain information on the bubble site density, departure diameter, and frequency of departure on

4 the different surfaces. On all the surfaces, the bubble site density and frequency of departure

5 increases sharply with temperature, while the diameter at departure stays relatively insensitive to

6 temperature. Correlations available in the literature were used as given, or modified to fit the

7 experimental data for the site density and diameter at departure, and extended them to the full

8 temperature range until CHF. Using the information on the bubble site density, departure

9 diameter, and frequency of departure, a simple heat flux partition model that neglects the effects

10 of bubble coalescence was applied to obtain the contribution of various modes of heat transfer to

11 the fluid from the various target surfaces. On the plain surfaces, both evaporative and quenching

12 components contribute nearly equally to the total heat flux. On the microporous surfaces, the

13 evaporative component contributes about $70 \%$ of the total heat, thus confirming that the

14 microporous coating enhances nucleate boiling heat transfer as a direct result of its significantly

15 higher active nucleation site density.

\section{Acknowledgments}

18 This work was performed under a subcontract from the National Renewable Energy

19 Laboratory (NREL) to the University of Colorado - Boulder. The authors thank the support of

20 Susan Rogers and Steven Boyd, Technology Development Managers of the Electric Drive

21 Technologies Program in the U.S. Department of Energy Vehicle Technologies Office. The

22 authors also thank Gilbert Moreno for help with the experimental apparatus, as well as Phil Tuma

$23(3 \mathrm{M})$, who supplied the target surfaces with the microporous coatings. 


\section{References}

2 [1] I. Mudawar, Assessment of high-heat-flux thermal management schemes, IEEE Trans.

3 Components Packag. Technol. 24 (2) (2001) 122-141.

4 [2] U.S. Department of Energy, Electrical and Electronics Technical Team Roadmap,

$5 \quad$ Washington D.C., 2013.

6 [3] J.R. Thome, Enhanced boiling heat transfer, Hemisphere Publishing Corporation, New $7 \quad$ York, 1990.

8 [4] H. Honda, J. Wei, Enhanced boiling heat transfer from electronic components by use of 9 surface microstructures, Exp. Therm. Fluid Sci. 28 (2004) 159-169.

10 [5] J. Tehver, H. Sui, V. Temkina, Heat transfer and hysteresis phenomena in boiling on 11 porous plasma-sprayed surface, Exp. Therm. Fluid Sci. 5 (6) (1992) 714-727.

12 [6] J.Y. Chang, S.M. You, Boiling heat transfer phenomena from microporous and porous 13 surfaces in saturated FC-72, Int. J. Heat Mass Transf. 40 (18) (1997) 4427-4447.

14 [7] K.N. Rainey, S.M. You, Effects of heater size and orientation on pool boiling heat transfer from microporous coated surfaces, Int. J. Heat Mass Transf. 44 (14) (2001) 2589-2599.

16 [8] M.S. El-Genk, Nucleate boiling enhancements on porous graphite and microporous and 17 macro-finned copper surfaces, Heat Transf. Eng. 33 (3) (2012) 175-204.

18 [9] A.E. Bergles, M.C. Chyu, Characteristics of nucleate pool boiling from porous metallic 19 coatings, J. Heat Transfer 104 (2) (1982) 279-285. 
1 [10] J.H. Kim, K.N. Rainey, S.M. You, J.Y. Pak, Mechanism of nucleate boiling heat transfer 2 enhancement from microporous surfaces in saturated FC-72, J. Heat Transfer 124 (3) 3 (2002) 500-506.

4 [11] S.J. Thiagarajan, S. Narumanchi, C. King, W. Wang, R. Yang, Enhancement of heat 5 transfer with pool and spray impingement boiling on microporous and nanowire surface 6 coatings, in: Proc. 14th Int. Heat Transf. Conf., Washington, D.C., 2010: pp. 1-10.

7 [12] S.J. Thiagarajan, S. Narumanchi, R. Yang, Effect of flow rate and subcooling on spray 8 heat transfer on microporous copper surfaces, Int. J. Heat Mass Transf. 69 (2014) 4939505.

10 [13] S.J.D. van Stralen, The mechanism of nucleate boiling in pure liquids and in binary 11 mixtures—part I, Int. J. Heat Mass Transf. 9 (10) (1966) 995-1006.

12 [14] B.B. Mikic, W.M. Rohsenow, P. Griffith, On bubble growth rates, Int. J. Heat Mass 13 Transf. 13 (4) (1970) 657-666.

14 [15] K.E. Forster, R. Greif, Heat transfer to a boiling liquid, J. Heat Transfer 81 (1959) 43-53.

15 [16] B.B. Mikic, W.M. Rohsenow, A new correlation of pool-boiling data including the effect 16 of heating surface characteristics, J. Heat Transfer 91 (2) (1969) 245-250.

17 [17] W.M. Rohsenow, A method of correlating heat transfer data for surface boiling of liquids, 18 J. Heat Transfer 74 (1952) 969-976. 
1 [18] H.K. Forster, N. Zuber, Dynamics of vapor bubbles and boiling heat transfer, AIChE J. 1 (4) (1955) 531-535.

3 [19] C.L. Tien, A hydrodynamic model for nucleate pool boiling, Int. J. Heat Mass Transf. 5 (6) (1962) 533-540.

5 [20] A. Luke, D.-C. Cheng, High speed video recording of bubble formation with pool boiling, Int. J. Therm. Sci. 45 (2006) 310-320.

7 [21] C. Gerardi, J. Buongiorno, L. Hu, T. McKrell, Study of bubble growth in water pool boiling through synchronized, infrared thermometry and high-speed video, Int. J. Heat Mass Transf. 53 (19-20) (2010) 4185-4192.

10 [22] J. McHale, S. Garimella, Nucleate boiling from smooth and rough surfaces-Part 2: 11 analysis of surface roughness effects on nucleate boiling, Exp. Therm. Fluid Sci. 44 (2013) 439-455.

13 [23] I. Mudawar, D. Bharathan, K. Kelly, S. Narumanchi, Two-phase spray cooling of hybrid vehicle electronics, IEEE Trans. Components Packag. Technol. 32 (2009) 501-512.

15 [24] 3M product brochure, 3M Novec ${ }^{\mathrm{TM}}$ engineered fluid HFE-7100 for heat transfer, (2002).

16 [25] C.Y. Ho, R.W. Powell, P.E. Liley, Thermal Conductivity of the Elements, J. Phys. Chem. $17 \quad$ Ref. Data 1 (2) (1972) 279.

18 [26] M.S. El-Genk, H. Bostanci, Saturation boiling of HFE-7100 from a copper surface, 19 simulating a microelectronic chip, Int. J. Heat Mass Transf. 46 (2003) 1841-1854. 
1 [27] 3M product brochure, 3M microporous metallic boiling enhancement coating (BEC) L2 20227, (2008).

3 [28] P.E. Tuma, Evaporator/boiler design for thermosyphons utilizing segregated hydrofluoroether working fluids, in: 22nd Annu. IEEE Semicond. Therm. Meas. Manag. Symp., 2006: pp. 69-77.

[29] S.J. Kline, F.A. McClintock, Describing uncertainties in single-sample experiments, Mech. Eng. 75 (1) (1953) 3-8.

[30] G. Moreno, S. Narumanchi, C. King, Pool boiling heat transfer characteristics of HFO1234yf on plain and microporous-enhanced surfaces, J. Heat Transfer 135 (11) (2013) 111014 .

11 [31] T.M. Anderson, I. Mudawar, Microelectronic cooling by enhanced pool boiling of a dielectric fluorocarbon liquid, J. Heat Transfer 111 (3) (1989) 752.

13 [32] J.H. Lienhard, V.K. Dhir, D.M. Riherd, Peak pool boiling heat-flux measurements on finite horizontal flat plates, J. Heat Transfer 95 (4) (1973) 477.

15 [33] J.H. Lienhard, V.K. Dhir, Hydrodynamic prediction of peak pool-boiling heat fluxes from finite bodies, J. Heat Transfer 95 (2) (1973) 152.

17 [34] R. Raj, J. Kim, Heater size and gravity based pool boiling regime map: transition criteria between buoyancy and surface tension dominated boiling, J. Heat Transfer 132 (9) (2010) 091503. 
1 [35] C.H. Wang, V.K. Dhir, Effect of surface wettability on active nucleation site density during pool boiling of water on a vertical surface, J. Heat Transfer 115 (3) (1993) 659.

3 [36] S.M. You, T.W. Simon, A. Bar-Cohen, W. Tong, Experimental investigation of nucleate 4 boiling incipience with a highly-wetting dielectric fluid (R-113), Int. J. Heat Mass Transf. $5 \quad 33(1990) 105-117$.

6 [37] Y.Y. Hsu, On the size range of active nucleation cavities on a heating surface, J. Heat $7 \quad$ Transfer 84 (3) (1962) 207-213.

[38] D. Gorenflo, E. Danger, A. Luke, S. Kotthoff, U. Chandra, C. Ranganayakulu, Bubble 9 formation with pool boiling on tubes with or without basic surface modifications for 10 enhancement, Int. J. Heat Fluid Flow 25 (2) (2004) 288-297.

11 [39] T. Hibiki, M. Ishii, Active nucleation site density in boiling systems, Int. J. Heat Mass 12 Transf. 46 (14) (2003) 2587-2601.

13 [40] G. Kocamustafaogullari, M. Ishii, Interfacial area and nucleation site density in boiling 14

15 [41] R.J. Benjamin, A.R. Balakrishnan, Nucleation site density in pool boiling of saturated 16 systems, Int. J. Heat Mass Transf. 26 (9) (1983) 1377-1387.

[42] W. Tong, A. Bar-Cohen, T.W. Simon, S.M. You, Contact angle effects on boiling 19 incipience of highly-wetting liquids, Int. J. Heat Mass Transf. 33 (1) (1990) 91-103. 
1 [43] R. Cole, Bubble frequencies and departure volumes at subatmospheric pressures, AIChE J. 13 (4) (1967) 779-783.

3 [44] S.S. Kutateladze, I.I. Gogonin, Growth rate and detachment diameter of a vapor bubble in free convection boiling of a saturated liquid, High Temp. 17 (1980) 667-671.

5 [45] M.K. Jensen, G.J. Memmel, Evaluation of bubble departure diameter correlations, in: Proc. 8th Int. Heat Transf. Conf., Begell House Inc., 1986: pp. 1907-1912.

[46] H.T. Phan, N. Caney, P. Marty, S. Colasson, J. Gavillet, How does surface wettability influence nucleate boiling?, Comptes Rendus Mécanique 337 (5) (2009) 251-259.

9 [47] S. Moghaddam, K. Kiger, Physical mechanisms of heat transfer during single bubble nucleate boiling of FC-72 under saturation conditions-I. Experimental investigation, Int. J.

12 [48] F.N. Peebles, H.J. Garber, Studies on the motion of gas bubbles in liquids, Chem. Eng. 13 Prog. 49 (1953) 88-97.

14 [49] V.P. Carey, Liquid-vapor phase-change phenomena: an introduction to the thermophysics 15 of vaporization and condensation processes in heat transfer equipment, 2nd ed., Taylor $16 \quad$ and Francis, New York, 2007.

17 [50] J.P. McHale, S. V. Garimella, Bubble nucleation characteristics in pool boiling of a 18 wetting liquid on smooth and rough surfaces, Int. J. Multiph. Flow 36 (4) (2010) 249-260. 
1 [51] R.W. Bowring, Physical model, based on bubble detachment, and calculation of steam

2 voidage in the subcooled region of a heated channel, in: HPR-10, Inst. Atomenergi,

3 Halden, Norw., 1962.

4 [52] W.H. McAdams, Heat transmission, 3rd ed., McGraw-Hill, New York, 1954.

5 [53] C.-Y. Han, P. Griffith, The mechanism of heat transfer in nucleate pool boiling-Part I, Int. J. Heat Mass Transf. 8 (6) (1965) 887-904.

7 [54] F. Demiray, J. Kim, Microscale heat transfer measurements during pool boiling of FC-72: effect of subcooling, Int. J. Heat Mass Transf. 47 (14-16) (2004) 3257-3268.

9 [55] S. Moghaddam, K. Kiger, Physical mechanisms of heat transfer during single bubble 10 nucleate boiling of FC-72 under saturation conditions-II: Theoretical analysis, Int. J. Heat 11 Mass Transf. 52 (5-6) (2009) 1295-1303. 


\section{Tables}

3

4 Table 1. Thermophysical properties of saturated HFE-7100 at various temperatures.

\begin{tabular}{|c|c|c|c|c|c|c|c|c|}
\hline $\begin{array}{l}T_{\text {sat }} \\
\left({ }^{\circ} \mathrm{C}\right)\end{array}$ & $\begin{array}{c}P_{\text {sat }} \\
(\mathrm{kPa})\end{array}$ & $\begin{array}{c}\text { Liquid } \\
\text { density } \\
\rho_{l} \\
\left(\mathrm{~kg} / \mathrm{m}^{3}\right)\end{array}$ & $\begin{array}{c}\text { Vapor } \\
\text { density } \\
\rho_{v} \\
\left(\mathrm{~kg} / \mathrm{m}^{3}\right)\end{array}$ & $\begin{array}{c}\text { Liquid } \\
\text { viscosity } \\
\mu_{l}(\mathrm{~Pa}-\mathrm{s})\end{array}$ & $\begin{array}{c}\text { Surface } \\
\text { tension } \sigma \\
(\mathrm{N} / \mathrm{m})\end{array}$ & $\begin{array}{c}\text { Thermal } \\
\text { conductivity } \\
\kappa_{l}(\mathrm{~W} / \mathrm{m}-\mathrm{K})\end{array}$ & $\begin{array}{l}\text { Specific } \\
\text { heat } C_{P} \\
(\mathrm{~J} / \mathrm{kg}-\mathrm{K})\end{array}$ & $\begin{array}{c}\text { Latent heat of } \\
\text { vaporization } \\
h_{l v}(\mathrm{~kJ} / \mathrm{kg})\end{array}$ \\
\hline 70 & 133 & 1394 & 12.5 & $3.5 \times 10^{-4}$ & $8.5 \times 10^{-3}$ & 0.06 & 1273 & 109 \\
\hline 61 & 100 & 1418 & 9.3 & $3.8 \times 10^{-4}$ & $9.3 \times 10^{-3}$ & 0.062 & 1254 & 112 \\
\hline 54 & 80 & 1438 & 7.7 & $4.1 \times 10^{-4}$ & $10.2 \times 10^{-3}$ & 0.063 & 1241 & 114 \\
\hline
\end{tabular}

7 Table 2. The range of superheat temperatures at onset of nucleate boiling on the different 8 surfaces, and the corresponding critical nucleating embryo sizes.

\begin{tabular}{|c|c|c|}
\hline Surface & $\begin{array}{c}\text { Range of } \\
\Delta T_{w, O N B}\left({ }^{\circ} \mathrm{C}\right)\end{array}$ & $\begin{array}{l}\text { Range of } \\
D_{c r i t}(\mu \mathrm{m})\end{array}$ \\
\hline Plain $\left(R_{a}=0.33 \mu \mathrm{m}\right)$ & $24.5-36.2$ & $0.17-0.35$ \\
\hline Plain $\left(R_{a}=0.78 \mu \mathrm{m}\right)$ & $14-24.3$ & $0.37-0.85$ \\
\hline Microporous $(100 \mu \mathrm{m})$ & $9-10.9$ & $1.2-1.6$ \\
\hline Microporous $(360 \mu \mathrm{m})$ & $3.4-10.1$ & $1.4-7$ \\
\hline Microporous (700 $\mu \mathrm{m})$ & $3.2-7$ & $2.3-7.8$ \\
\hline
\end{tabular}

10

11 


\section{$1 \quad$ List of Figures} 11 levels. Credit: (a, b) Suraj Thiagarajan; (c, d) Bobby To (NREL). microporous layer. exposed on top. Photo credit: Suraj Thiagarajan (NREL). surface gives $16.7 \mathrm{~W} / \mathrm{cm}^{2}$.......

Fig. 1. Schematic diagram showing the different modes of heat and mass transfer on (a) plain surface and (b) inside and outside the microporous surface. In addition to the modes of heat transfer shown in the figure, bubble pumping action results in convective heat transfer inside the 42

Fig. 2. (a) Schematic diagram and (b) photograph of the pool boiling facility. Inset in (b) shows the photograph of the test heater assembly with the $2 \mathrm{~mm} \times 10 \mathrm{~mm}$ copper surface

Fig. 3. Scanning electron microscope images of (a) plain surface of $R_{a}=0.33 \mu \mathrm{m}$ and (b) plain surface of $R_{a}=0.78 \mu \mathrm{m}$; (c) and (d) microporous surface at two different magnification

Fig. 4. Results of steady-state thermal simulation: two cases, corresponding to heat input (1) $q_{\text {in }}=1.74 \mathrm{~W}$ (with $\left.h=4,200 \mathrm{~W} / \mathrm{m}^{2}-\mathrm{K}\right)$ and (2) $q_{\text {in }}=5.83 \mathrm{~W}$ (with $h=13,200 \mathrm{~W} / \mathrm{m}^{2}-\mathrm{K}$ ) are shown. (a) Boundary conditions applied to the various portions of the heater assembly, (b) temperature contour in the copper block in the direction of heat transfer; (c) and (d) show the temperature contour plots in the plane perpendicular to the direction of heat conduction at thermocouple location: $\left(\mathrm{T}_{1}\right) 4 \mathrm{~mm}$ from the surface and $\left(\mathrm{T}_{2}\right) 1 \mathrm{~mm}$ from the surface, respectively.

Fig. 5. Pool boiling curves on plain surface with target surface dimension of $10 \mathrm{~mm} \times 10$ $\mathrm{mm}$. A comparison is made with data from [26]. Inset shows the schematic of the cross-section of the test heater assembly. Data for the smooth plain surface of dimension $2 \mathrm{~mm} \times 10 \mathrm{~mm}$ are shown here for comparison. The Lienhard-Dhir correlation for CHF on an infinitely large flat 
Fig. 6. (a) Pool boiling curves and (b) heat transfer coefficients for the various surfaces.

2 Arrows denote CHF. Horizontal bars indicate the range of the onset of nucleate boiling superheat

3 in different test runs.

4 Fig. 7. Predicted size range of active cavity sites as a function of wall superheat based on

5 Hsu's criterion, for the range of contact angle $1^{\circ}<\phi<50^{\circ}$. The active sites are located in the

6 concave portion of each curve. The range of critical diameters of the nucleating embryo

7 calculated using Eq. (5) for each of the different surfaces from the superheat temperature at ONB

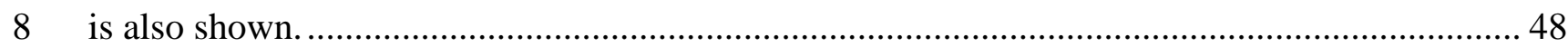

9 Fig. 8. Images of bubble dynamics on a plain and a microporous surface at various heat flux

10 levels. Credit: Suraj Thiagarajan (NREL).

11 Fig. 9. Experimental measurements of bubble site density compared with correlations for the

12 two plain surfaces of roughness (a) $0.33 \mu \mathrm{m}$ and (b) $0.78 \mu \mathrm{m}$. The extended range corresponds to

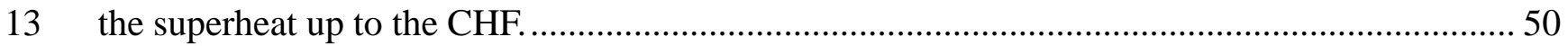

14 Fig. 10. Experimental measurements of bubble site density compared with correlations for

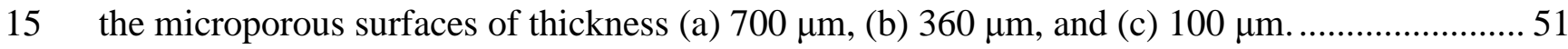

16 Fig. 11. Bubble site density at departure on the various surfaces as measured using the high-

17 speed video. The symbols are the measurements and the solid lines are the fits based on the H-I

18 correlation as explained in section 3.2.1. $N_{\max }$ represents the maximum bubble site density when

19 the surface is fully covered by bubbles at the respective departure diameter.......................... 52

20 Fig. 12. (a) Representative distribution of departure diameters on plain and microporous

21 surfaces. (b) Average bubble departure diameter for the various surfaces. Predictions based on

22 several different models are also shown. The best agreement was found using the model from

23 Phan et al. [46] with the same contact angle as used for the nucleate site density correlations... 53 
Fig. 13. Average frequency of bubble departure for the various surfaces as a function of the

2 superheat. The solid lines and equations in each case represent linear data fits

3 Fig. 14. The partition of heat flux model applied to the plain surfaces: (a) smooth $\left(R_{a}=0.33\right.$

$4 \mu \mathrm{m})$ and (b) rough $\left(R_{a}=0.78 \mu \mathrm{m}\right)$. The solid line with * markers is the experimental data. The

5 solid markers denote the data points of $N, D$, and $f$ from experiments, and the open symbols

6 denote the data from extrapolated $N, D$, and $f$.

7 Fig. 15. The partition of heat flux model applied to the microporous surfaces: (a) $700 \mu \mathrm{m}$, (b)

$8360 \mu \mathrm{m}$, and (c) $100 \mu \mathrm{m}$. The solid line with * markers is the experimental data. The solid

9 markers denote the data points of $N, D$, and $f$ from experiments, and the open symbols denote the

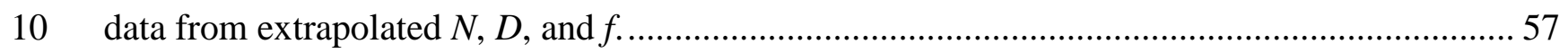




\section{$1 \quad$ Figures}

(a)

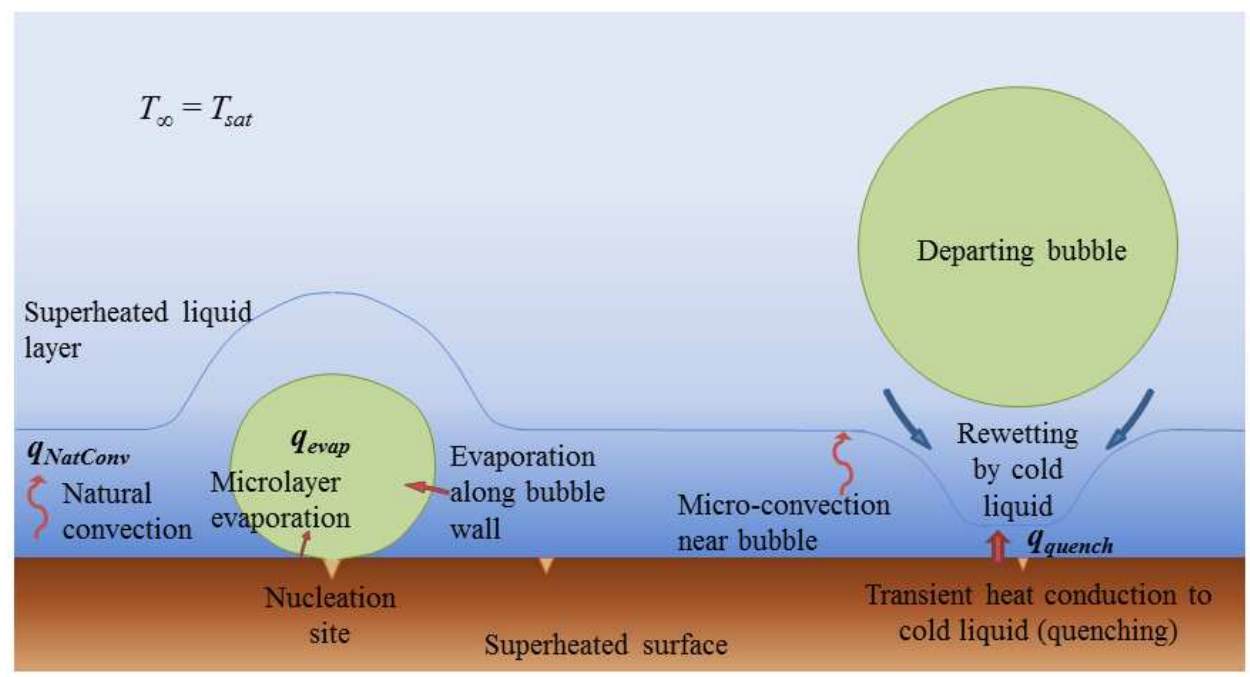

(b)

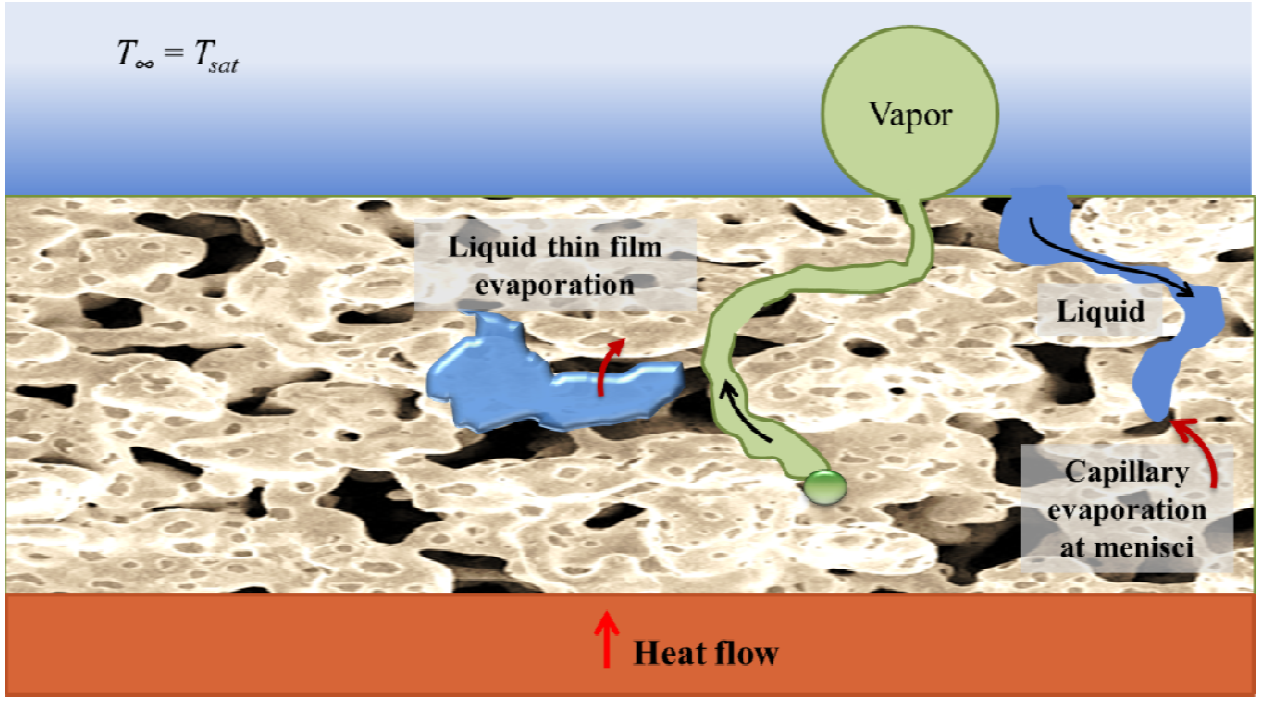

Fig. 1. Schematic diagram showing the different modes of heat and mass transfer on (a) plain

4 surface and (b) inside and outside the microporous surface. In addition to the modes of heat

5 transfer shown in the figure, bubble pumping action results in convective heat transfer inside the

6 microporous layer. 
(a)

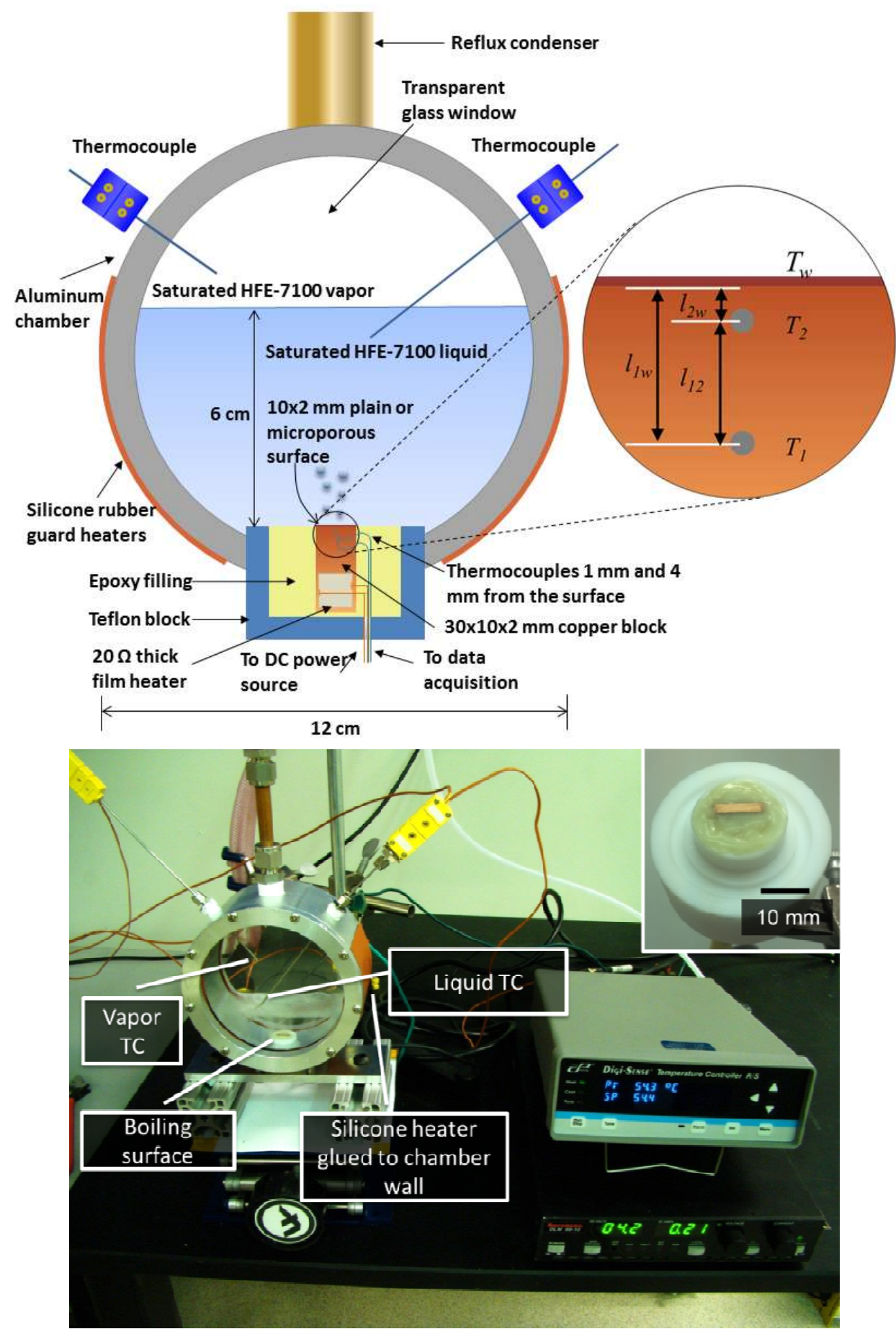

Fig. 2. (a) Schematic diagram and (b) photograph of the pool boiling facility. Inset in (b)

2 shows the photograph of the test heater assembly with the $2 \mathrm{~mm} \times 10 \mathrm{~mm}$ copper surface

3 exposed on top. Photo credit: Suraj Thiagarajan (NREL). 


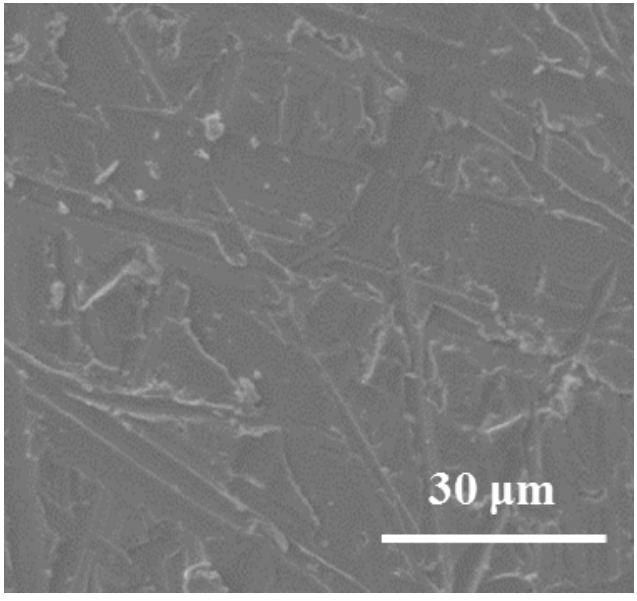

(a)

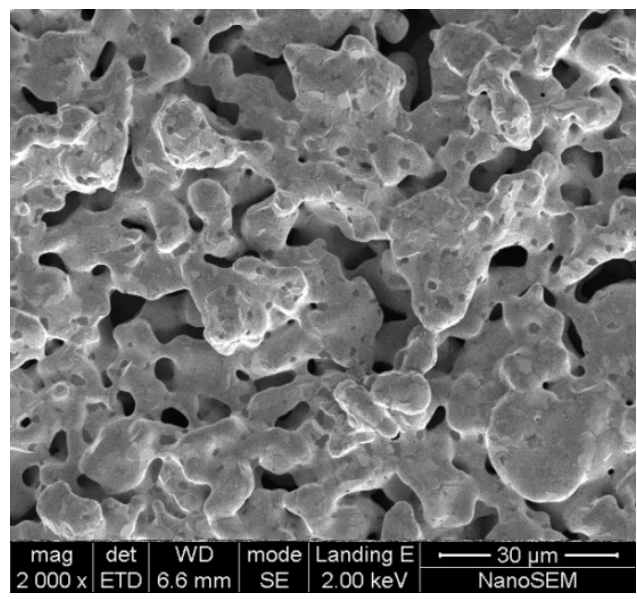

(c)

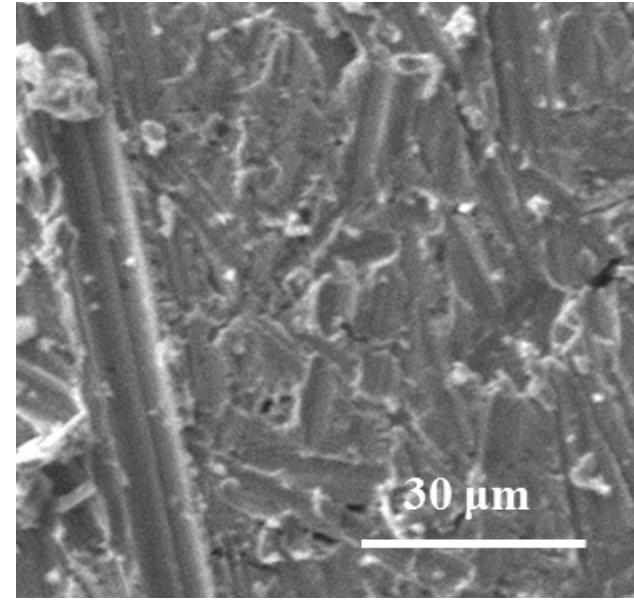

(b)

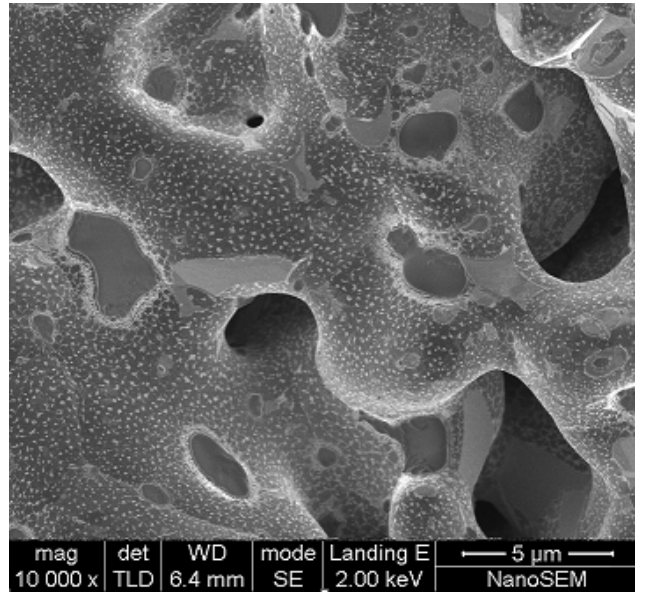

(d)

2 Fig. 3. Scanning electron microscope images of (a) plain surface of $R_{a}=0.33 \mu \mathrm{m}$ and (b)

3 plain surface of $R_{a}=0.78 \mu \mathrm{m}$; (c) and (d) microporous surface at two different magnification

4 levels. Credit: (a, b) Suraj Thiagarajan; (c, d) Bobby To (NREL). 


\section{Case 1:}

Heat input $q_{\text {in }}=1.74 \mathrm{~W}$;

Heat flux on surface $q "=5.8 \mathrm{~W} / \mathrm{cm}^{2}$
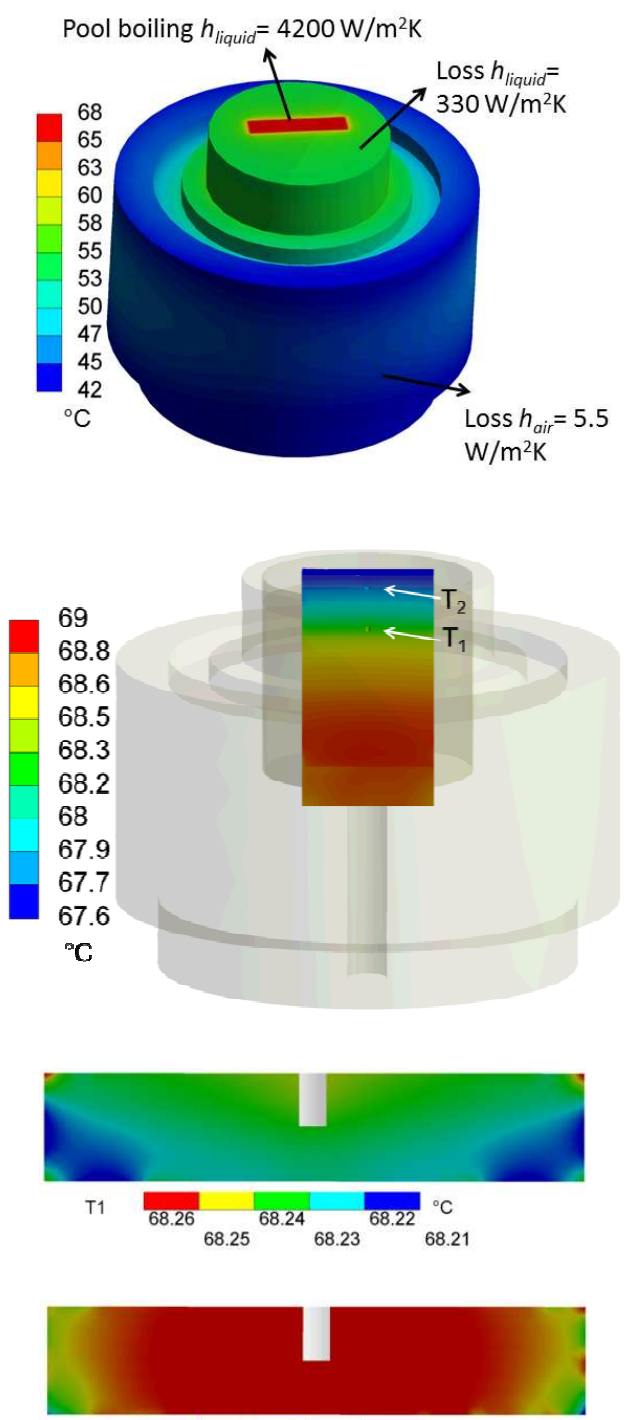

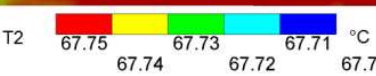

\section{Case 2:}

Heat input $q_{\text {in }}=5.83 \mathrm{~W}$;

Heat flux on surface $q "=26 \mathrm{~W} / \mathrm{cm}^{2}$

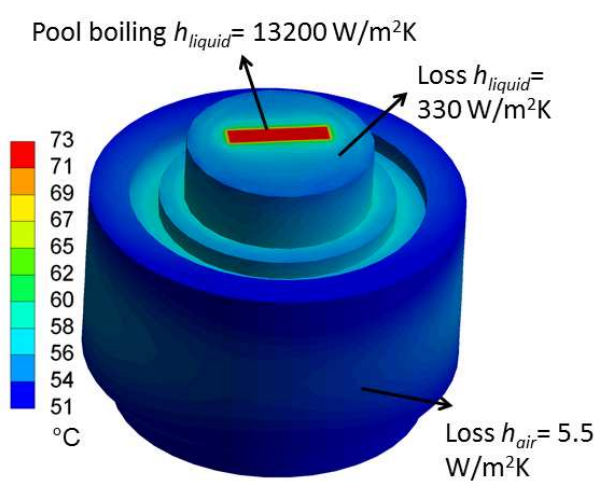

(b)

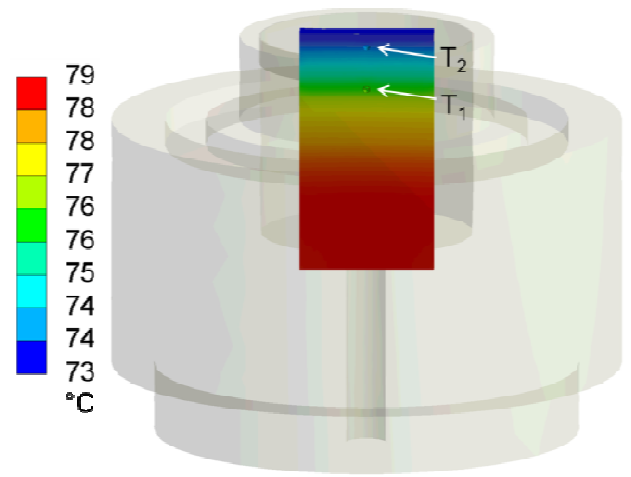

(c)
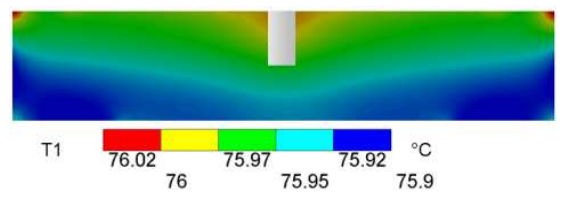

(d)

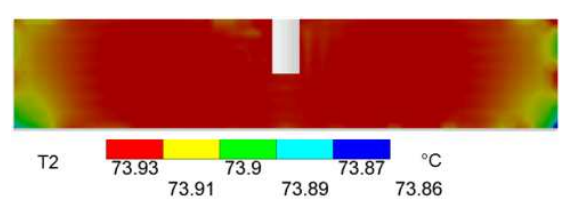

Fig. 4. Results of steady-state thermal simulation: two cases, corresponding to heat input (1)

$2 q_{\text {in }}=1.74 \mathrm{~W}$ (with $h=4,200 \mathrm{~W} / \mathrm{m}^{2}-\mathrm{K}$ ) and (2) $q_{\text {in }}=5.83 \mathrm{~W}$ (with $h=13,200 \mathrm{~W} / \mathrm{m}^{2}-\mathrm{K}$ ) are

3 shown. (a) Boundary conditions applied to the various portions of the heater assembly, (b)

4 temperature contour in the copper block in the direction of heat transfer; (c) and (d) show the

5 temperature contour plots in the plane perpendicular to the direction of heat conduction at

6 thermocouple location: $\left(T_{1}\right) 4 \mathrm{~mm}$ from the surface and $\left(T_{2}\right) 1 \mathrm{~mm}$ from the surface, respectively. 


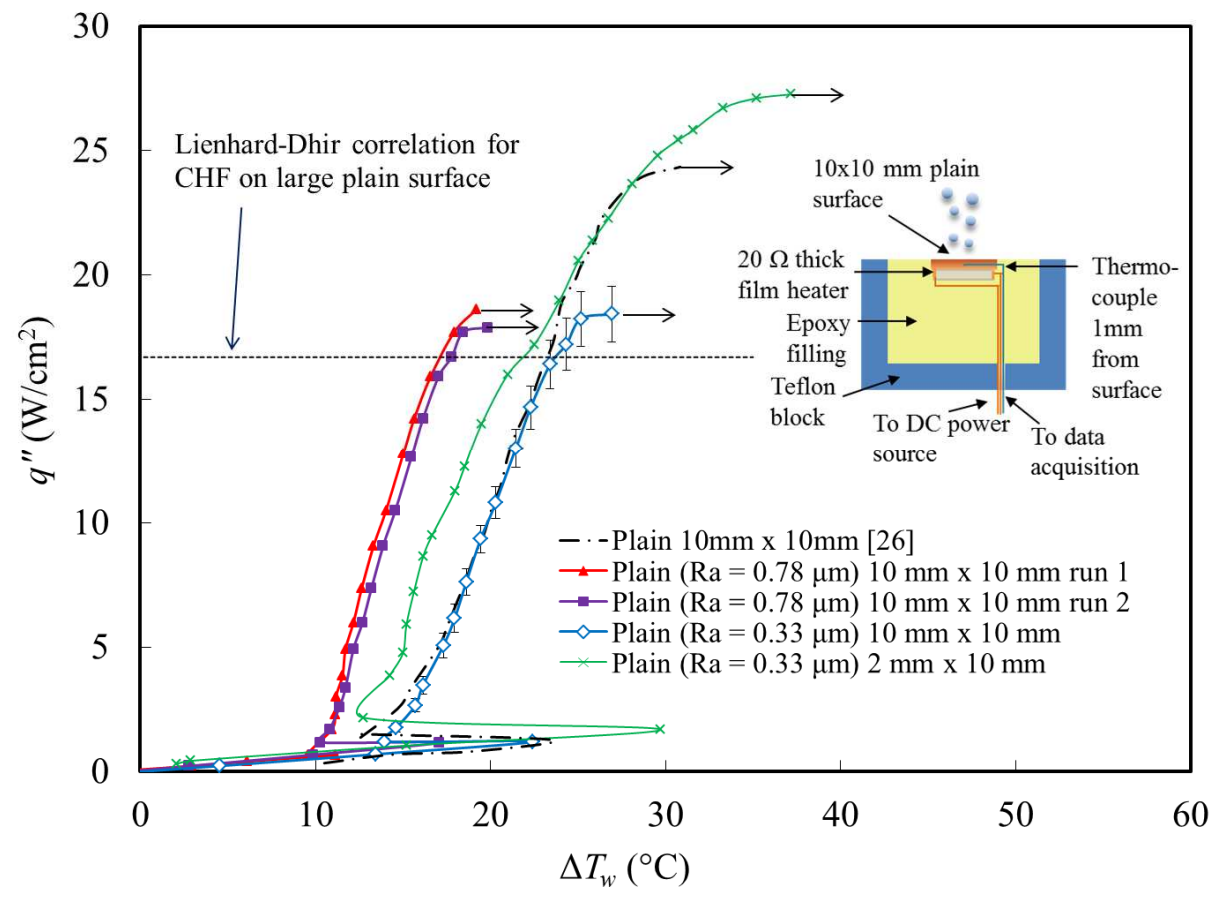

2

3 Fig. 5. Pool boiling curves on plain surface with target surface dimension of $10 \mathrm{~mm} \times 10$

$4 \mathrm{~mm}$. A comparison is made with data from [26]. Inset shows the schematic of the cross-section of

5 the test heater assembly. Data for the smooth plain surface of dimension $2 \mathrm{~mm} \times 10 \mathrm{~mm}$ are

6 shown here for comparison. The Lienhard-Dhir correlation for CHF on an infinitely large flat

7 surface gives $16.7 \mathrm{~W} / \mathrm{cm}^{2}$. 
(a)

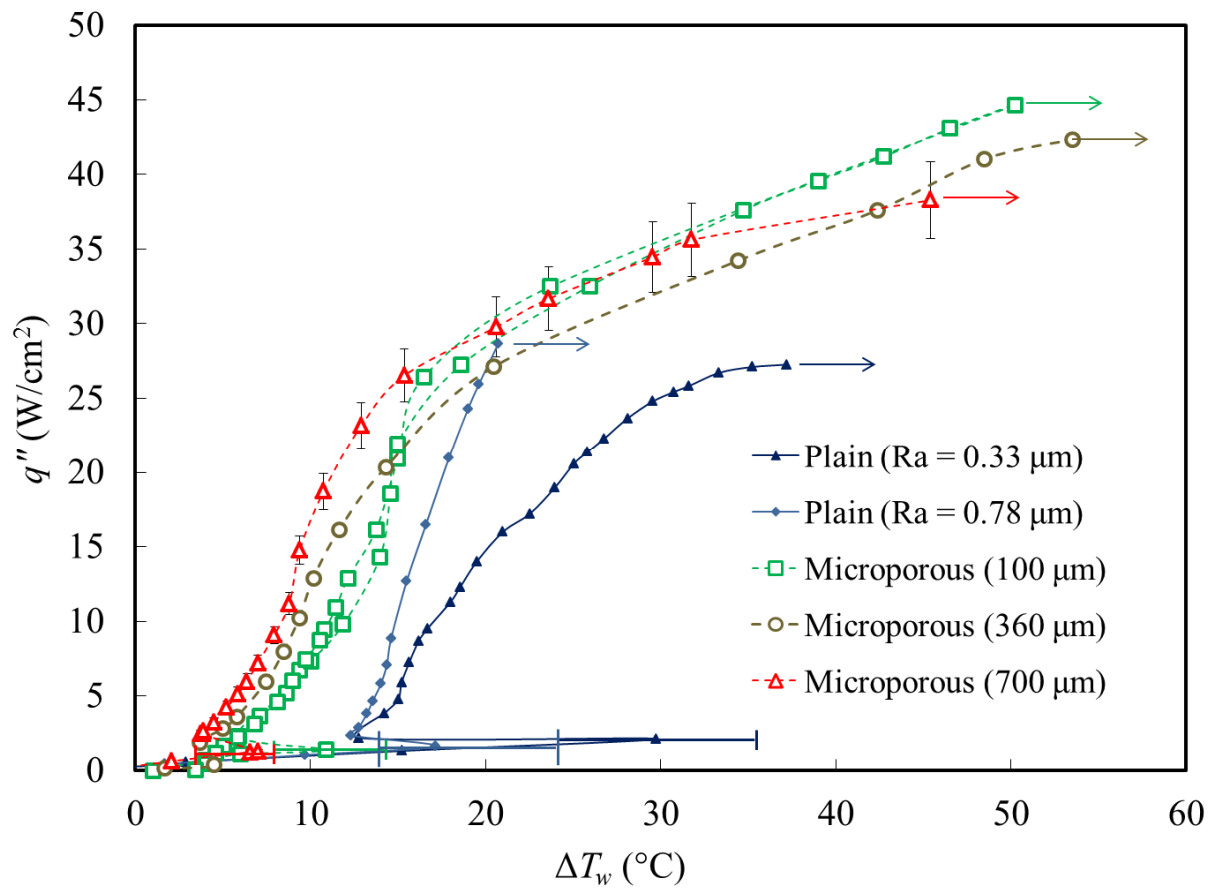

(b)

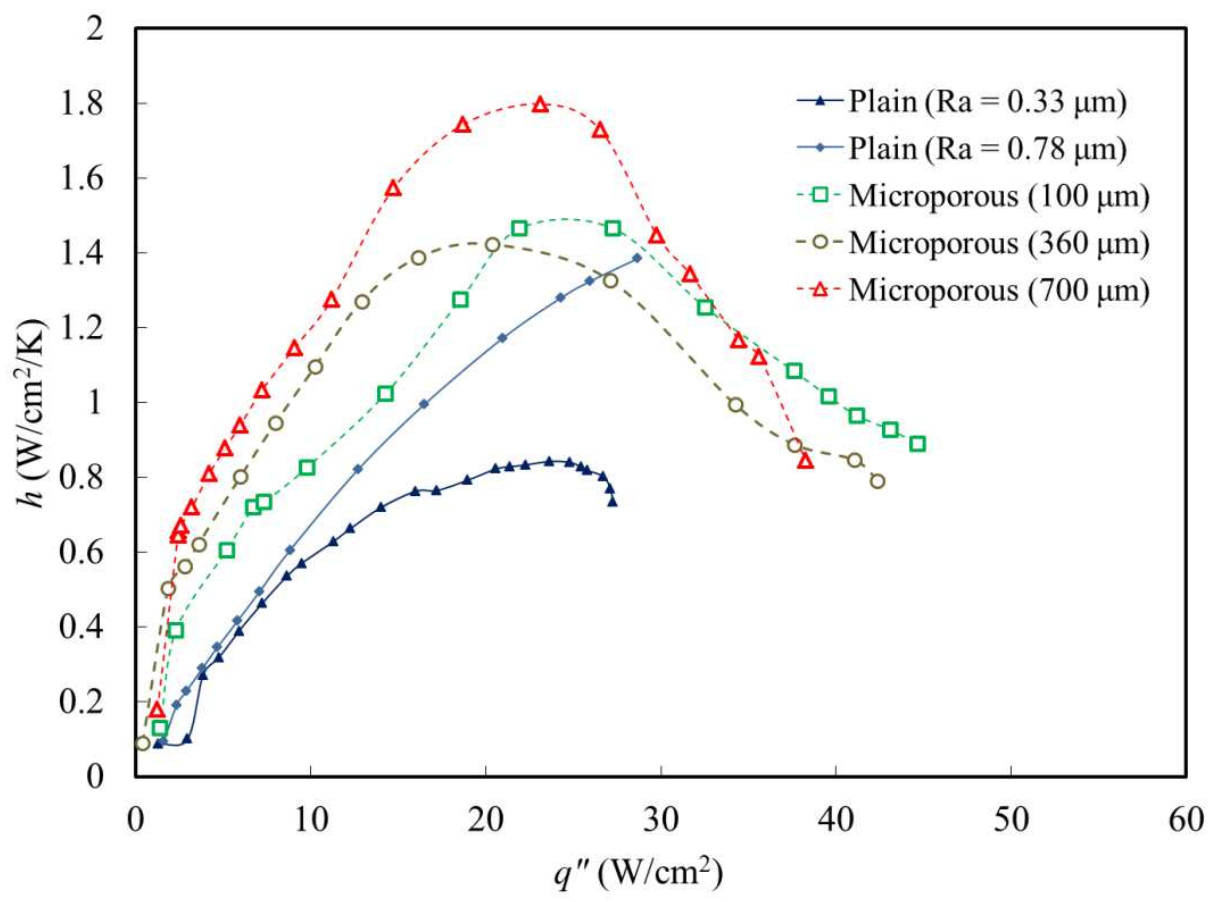

Fig. 6. (a) Pool boiling curves and (b) heat transfer coefficients for the various surfaces.

2 Arrows denote CHF. Horizontal bars indicate the range of the onset of nucleate boiling superheat

3 in different test runs. 


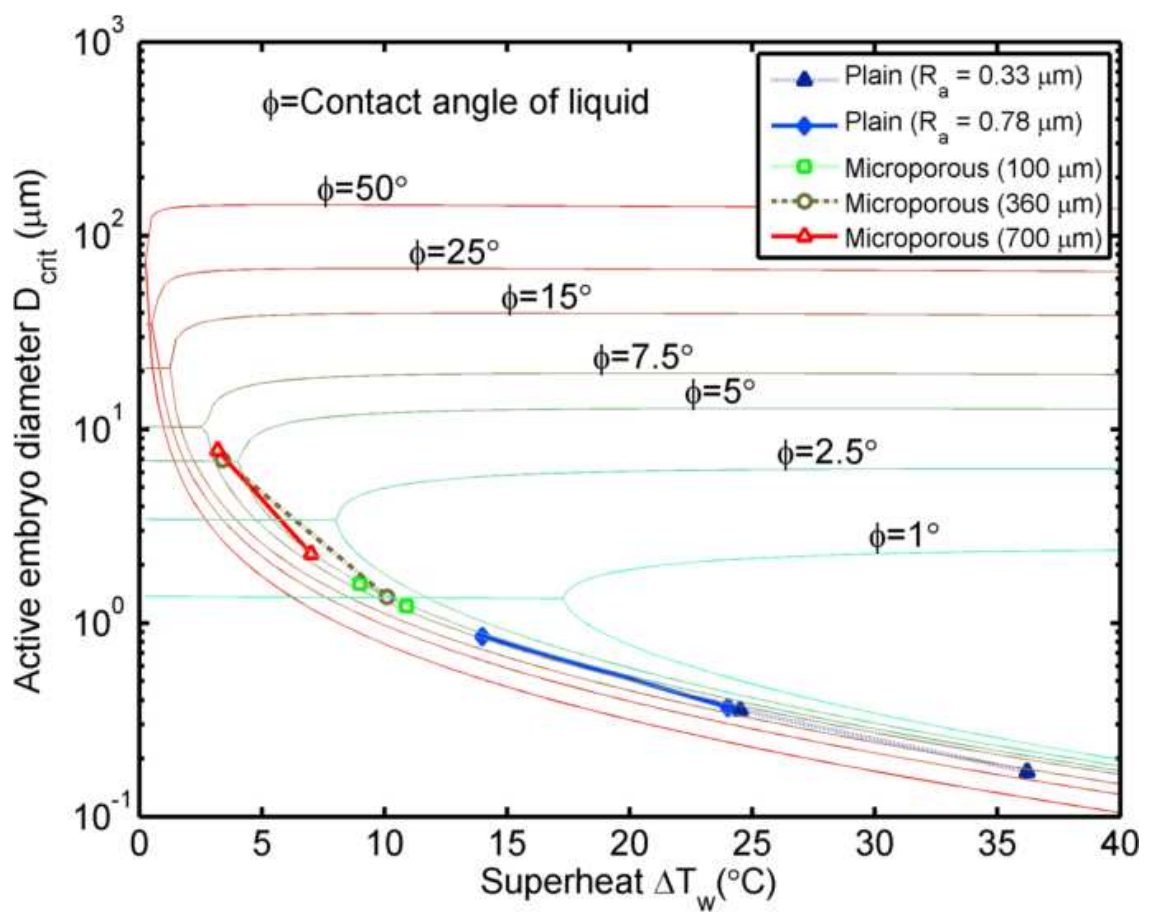

3 Fig. 7. Predicted size range of active cavity sites as a function of wall superheat based on

4 Hsu's criterion, for the range of contact angle $1^{\circ}<\phi<50^{\circ}$. The active sites are located in the

5 concave portion of each curve. The range of critical diameters of the nucleating embryo

6 calculated using Eq. (5) for each of the different surfaces from the superheat temperature at ONB

7 is also shown. 
Plain $(0.33 \mu \mathrm{m})$

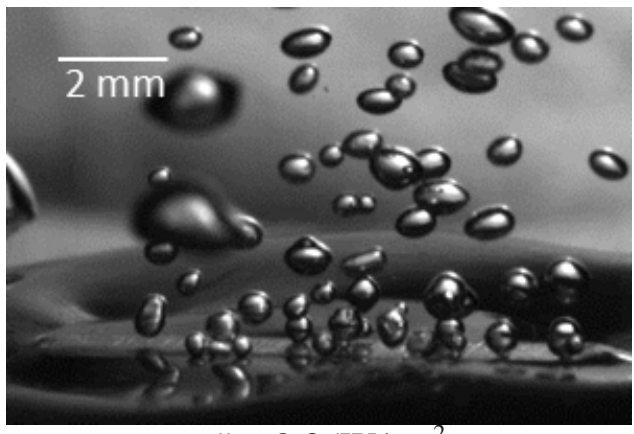

$q^{\prime \prime}=2.35 \mathrm{~W} / \mathrm{cm}^{2}$

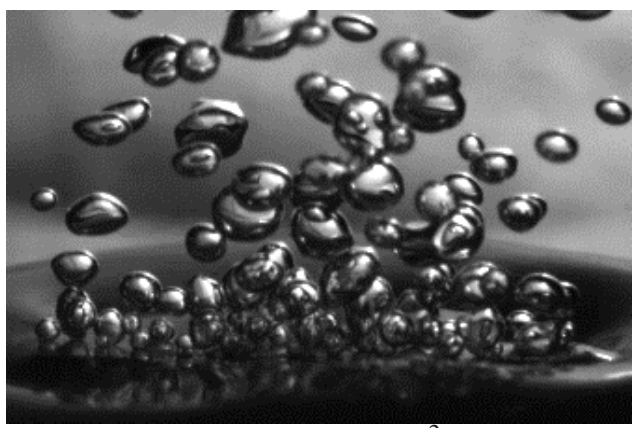

$q^{\prime \prime}=5.9 \mathrm{~W} / \mathrm{cm}^{2}$

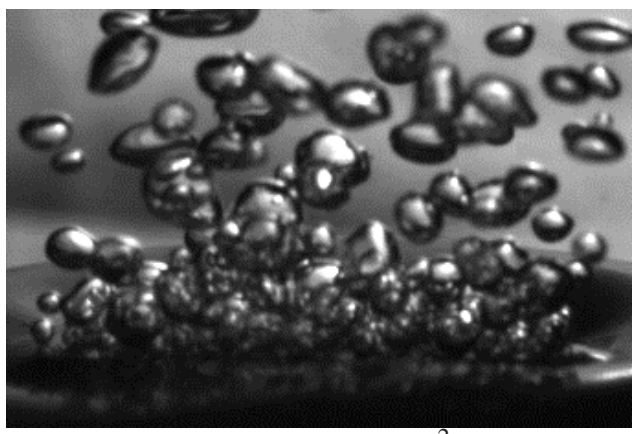

$q "=7.24 \mathrm{~W} / \mathrm{cm}^{2}$

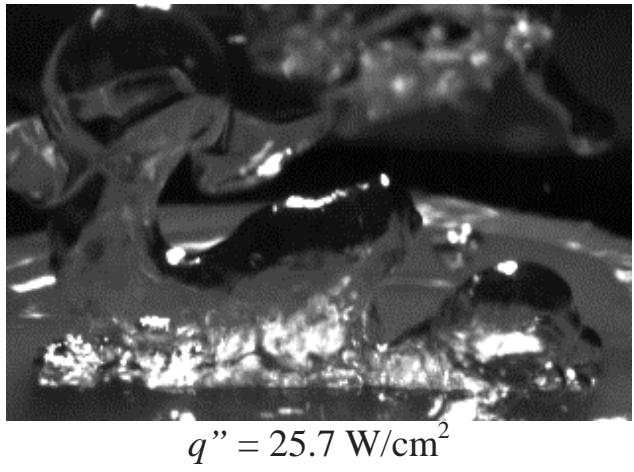

(near CHF)
Microporous $(700 \mu \mathrm{m})$
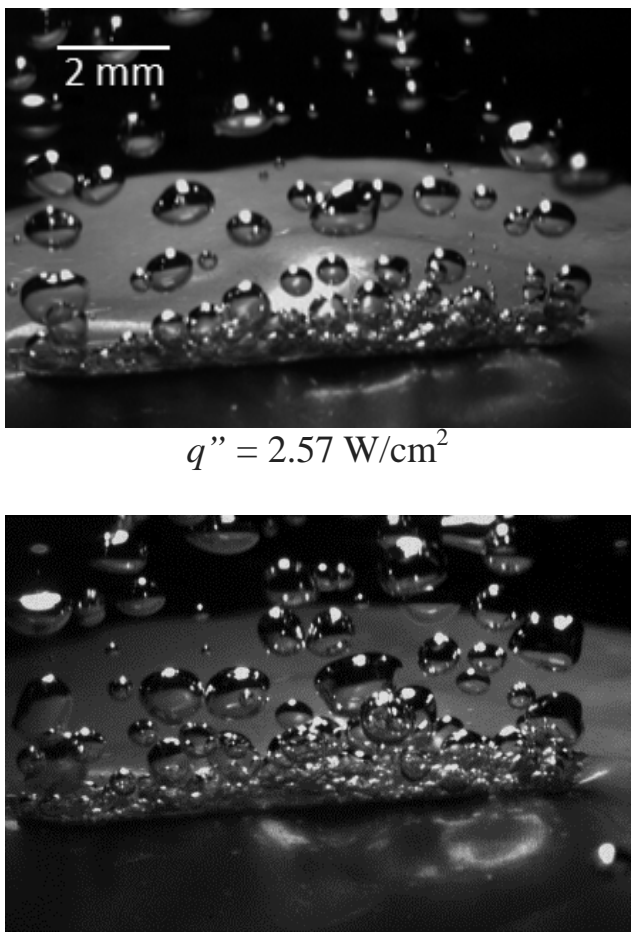

$q^{\prime}=4.25 \mathrm{~W} / \mathrm{cm}^{2}$
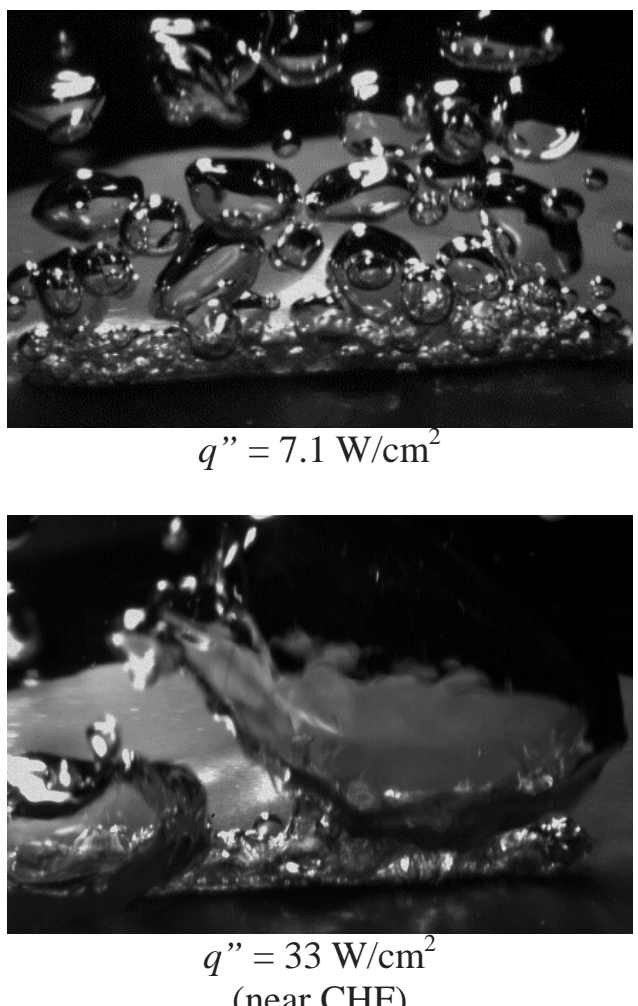

Fig. 8. Images of bubble dynamics on a plain and a microporous surface at various heat flux 2 levels. Credit: Suraj Thiagarajan (NREL). 
(a)

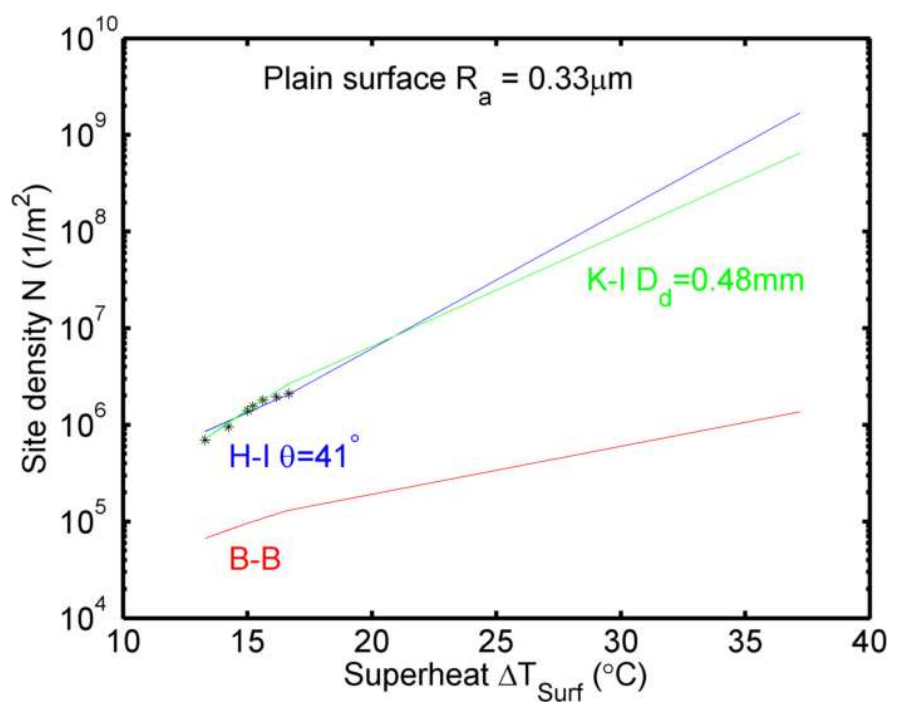

(b)

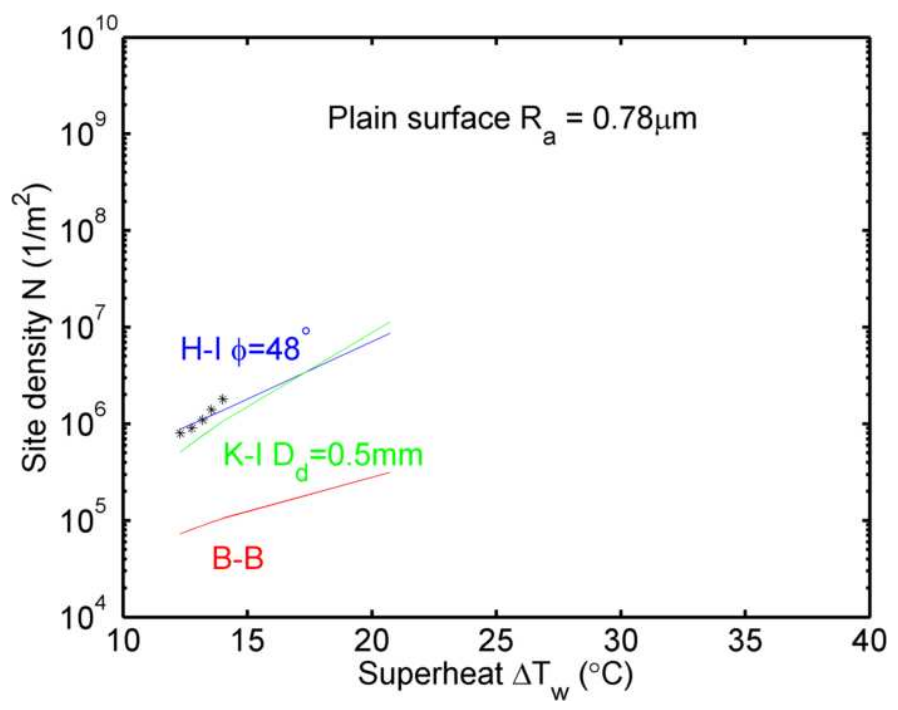

1 Fig. 9. Experimental measurements of bubble site density compared with correlations for the

2 two plain surfaces of roughness (a) $0.33 \mu \mathrm{m}$ and (b) $0.78 \mu \mathrm{m}$. The extended range corresponds to 3 the superheat up to the CHF. 


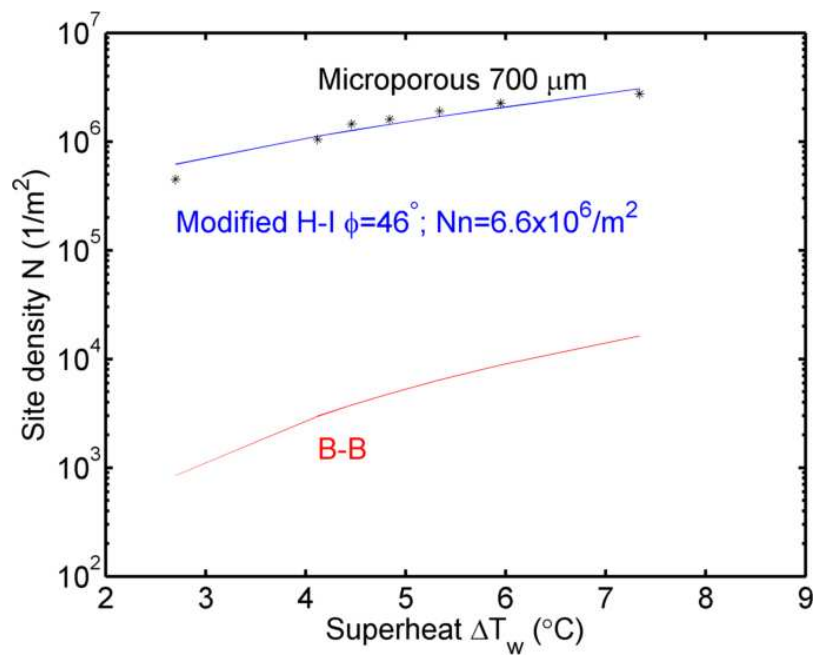

(a)

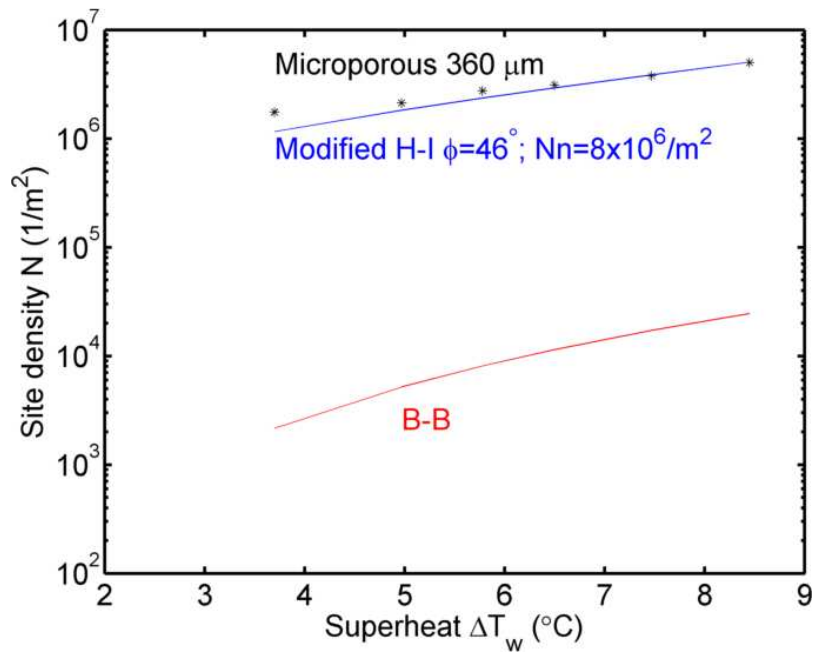

(b)

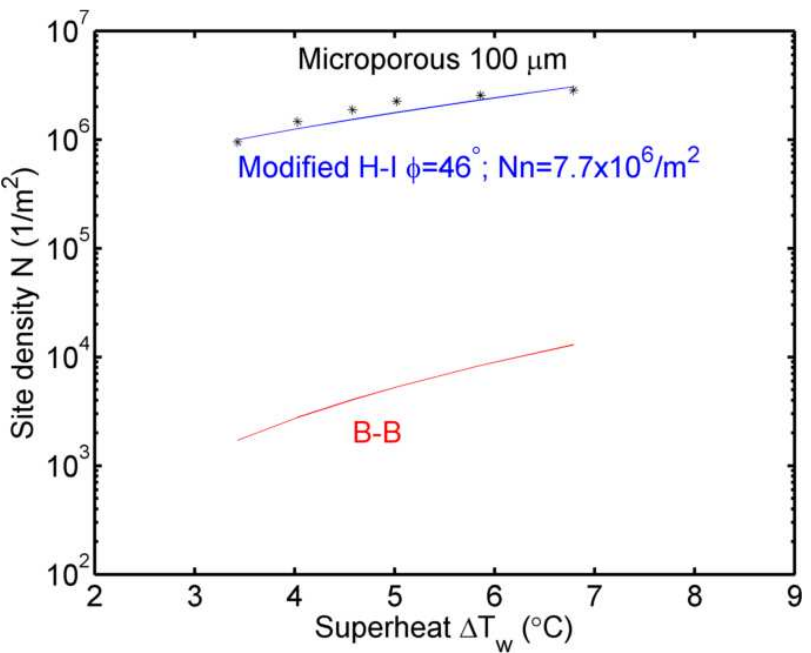

(c)

Fig. 10. Experimental measurements of bubble site density compared with correlations for

2 the microporous surfaces of thickness (a) $700 \mu \mathrm{m}$, (b) $360 \mu \mathrm{m}$, and (c) $100 \mu \mathrm{m}$.

3 


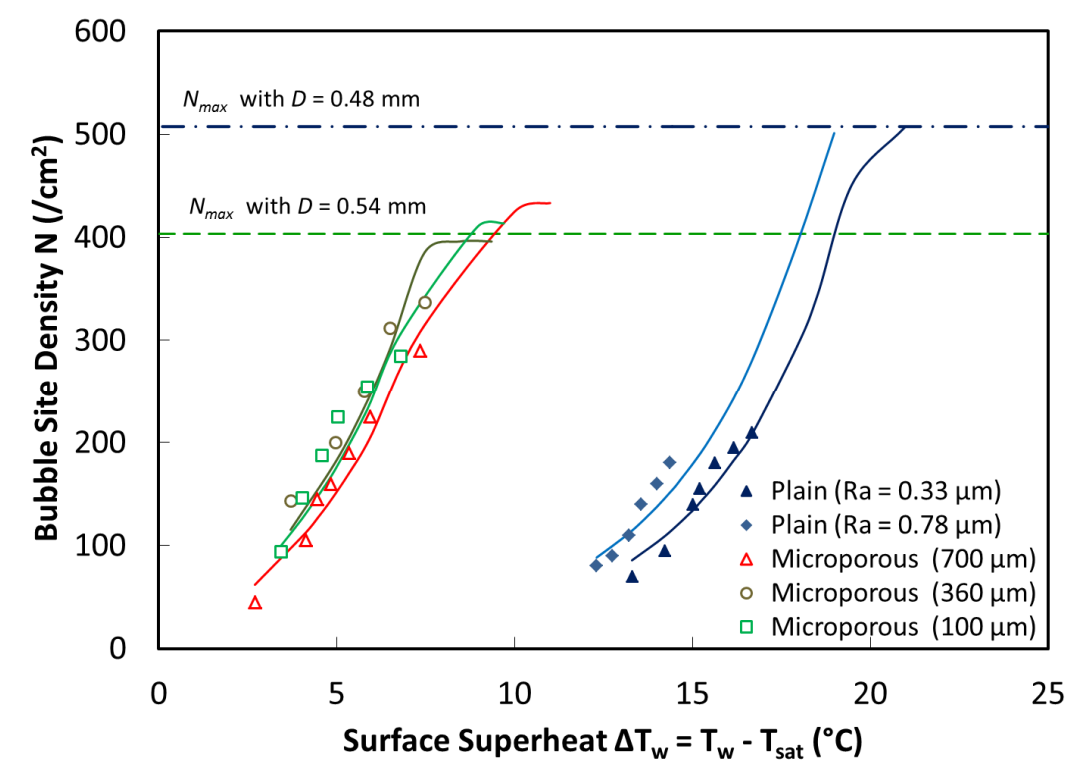

4 Fig. 11. Bubble site density at departure on the various surfaces as measured using the high-

5 speed video. The symbols are the measurements and the solid lines are the fits based on the H-I

6 correlation as explained in section 3.2.1. $N_{\max }$ represents the maximum bubble site density when

7 the surface is fully covered by bubbles at the respective departure diameter. 
(a)

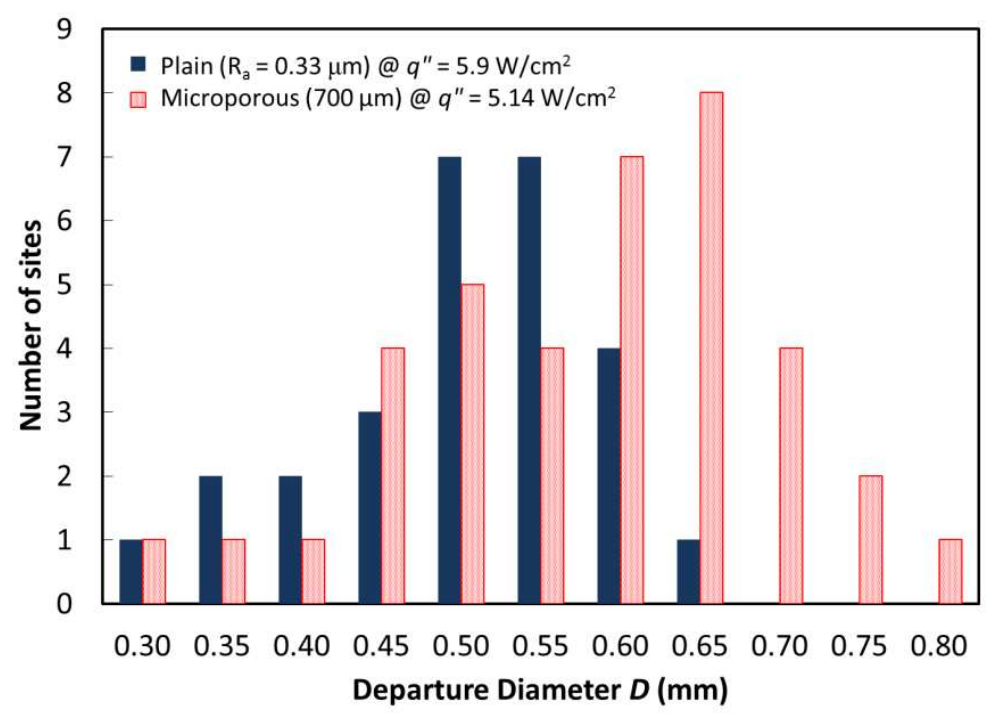

(b)

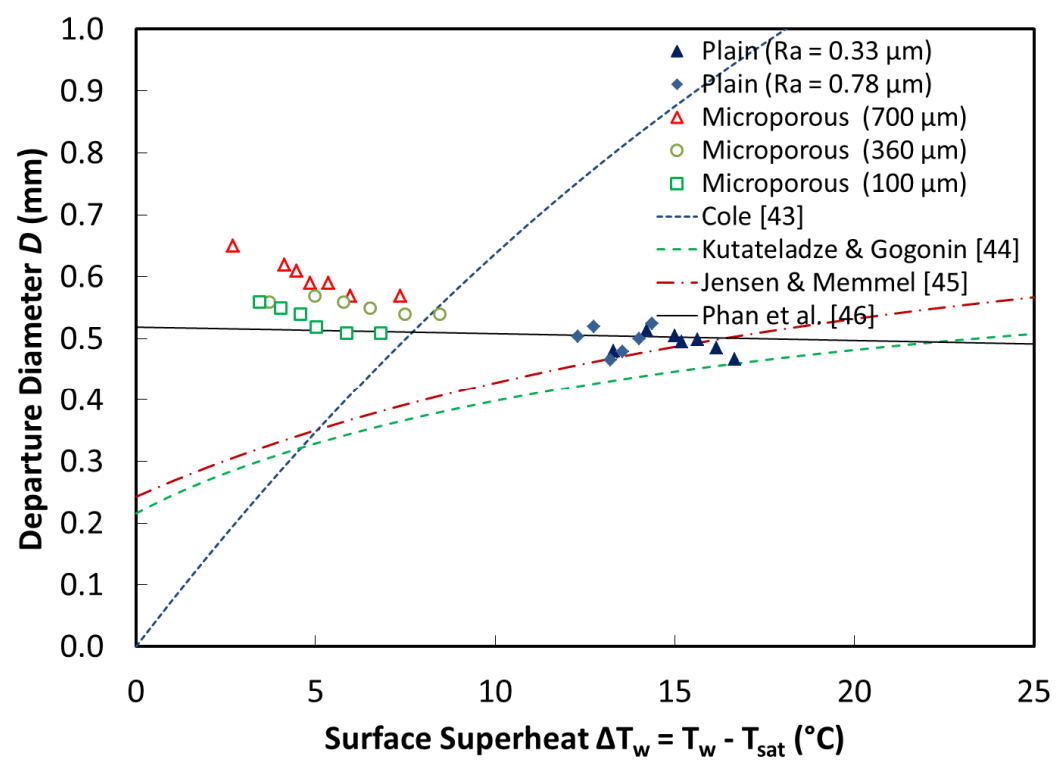

Fig. 12. (a) Representative distribution of departure diameters on plain and microporous

2 surfaces. (b) Average bubble departure diameter for the various surfaces. Predictions based on

3 several different models are also shown. The best agreement was found using the model from

4 Phan et al. [46] with the same contact angle as used for the nucleate site density correlations. 


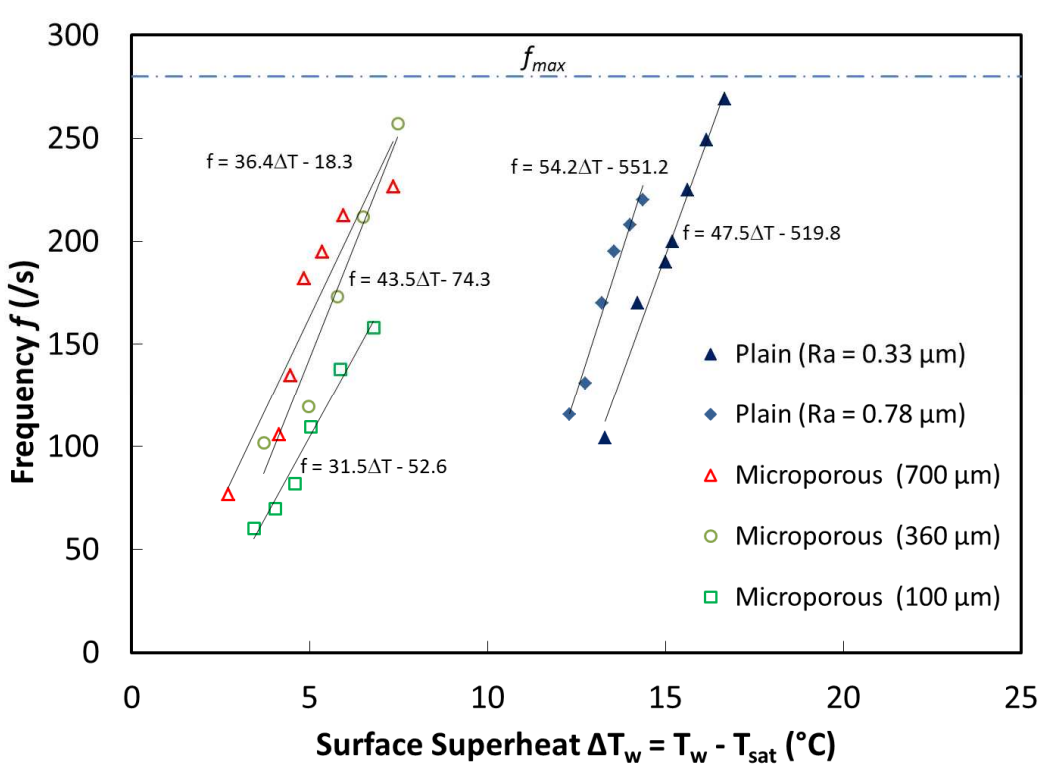

2

3 Fig. 13. Average frequency of bubble departure for the various surfaces as a function of the

4 superheat. The solid lines and equations in each case represent linear data fits. 
(a) Plain smooth

$\left(R_{a}=0.33 \mu \mathrm{m}\right)$

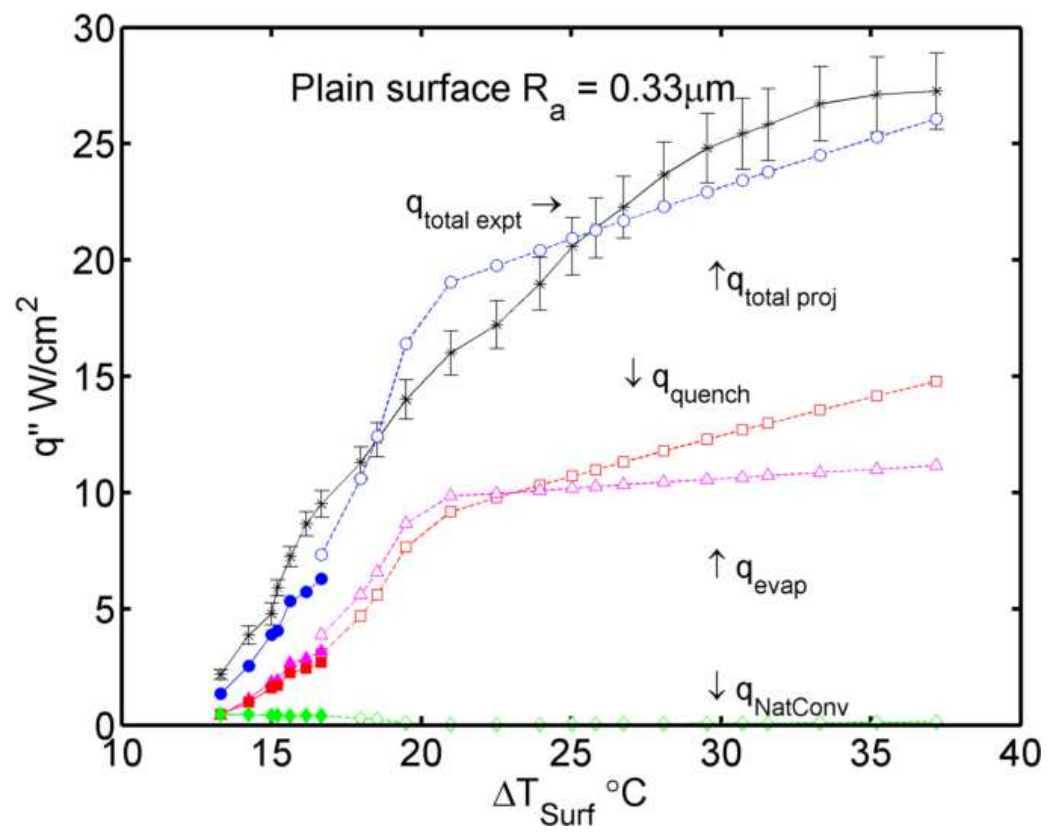

(b) Plain rough

$\left(R_{a}=0.78 \mu \mathrm{m}\right)$

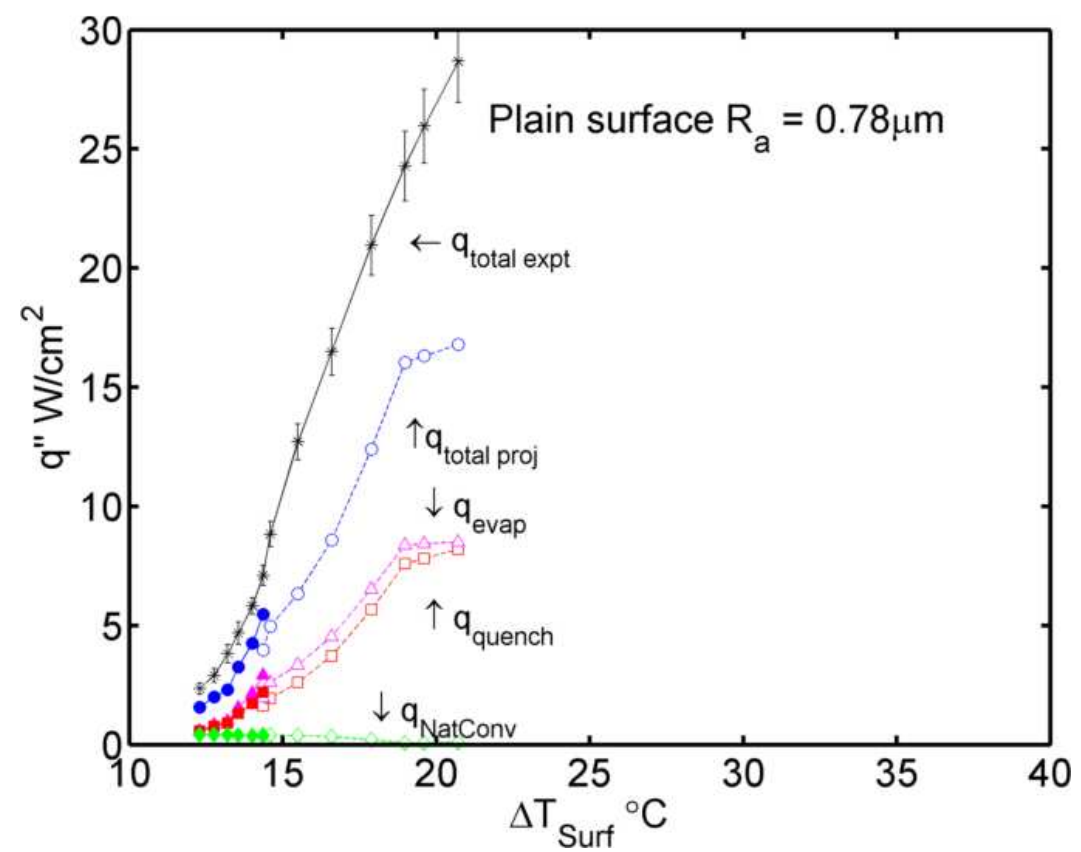

Fig. 14. The partition of heat flux model applied to the plain surfaces: (a) smooth $\left(R_{a}=0.33\right.$

$2 \mu \mathrm{m})$ and (b) rough $\left(R_{a}=0.78 \mu \mathrm{m}\right)$. The solid line with * markers is the experimental data. The

3 solid markers denote the data points of $N, D$, and $f$ from experiments, and the open symbols

4 denote the data from extrapolated $N, D$, and $f$. 
(a) $700 \mu \mathrm{m}$

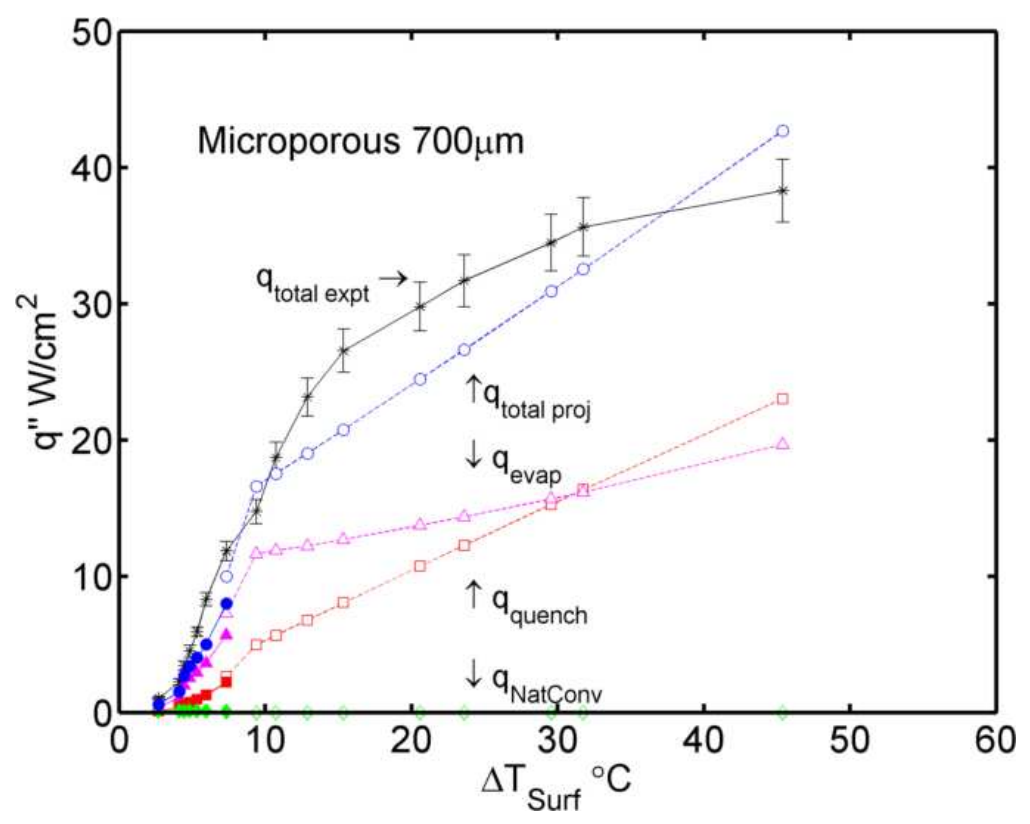

(b) $360 \mu \mathrm{m}$

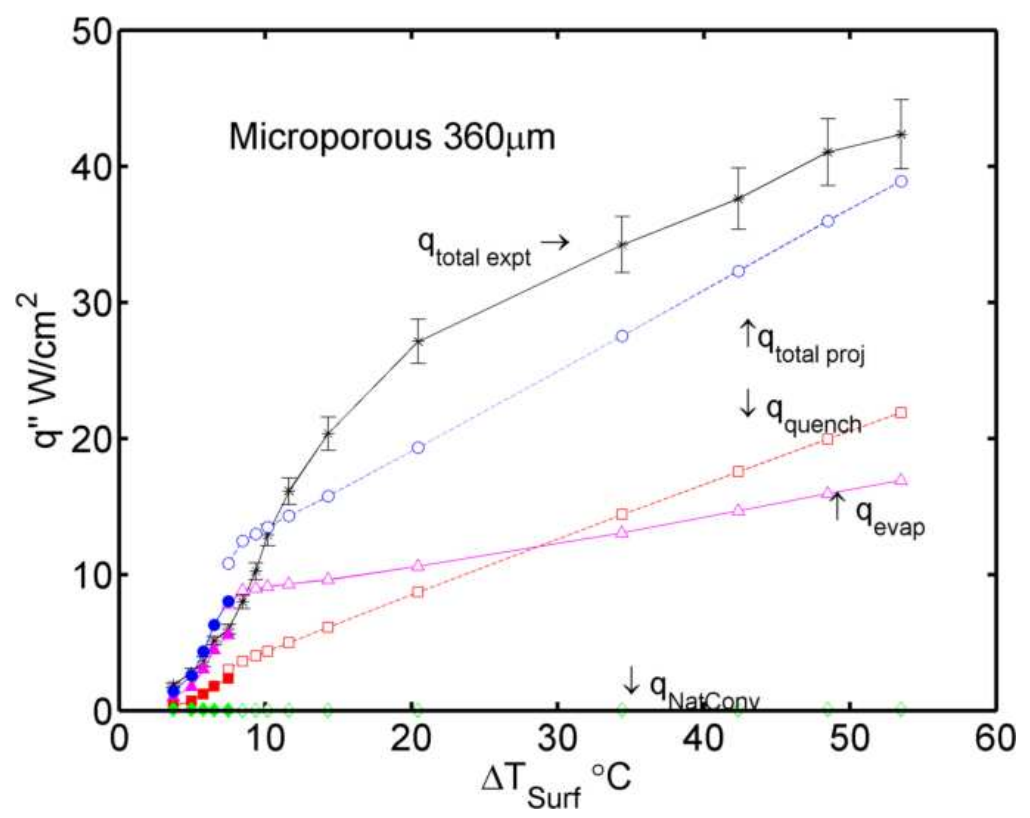


(c) $100 \mu \mathrm{m}$

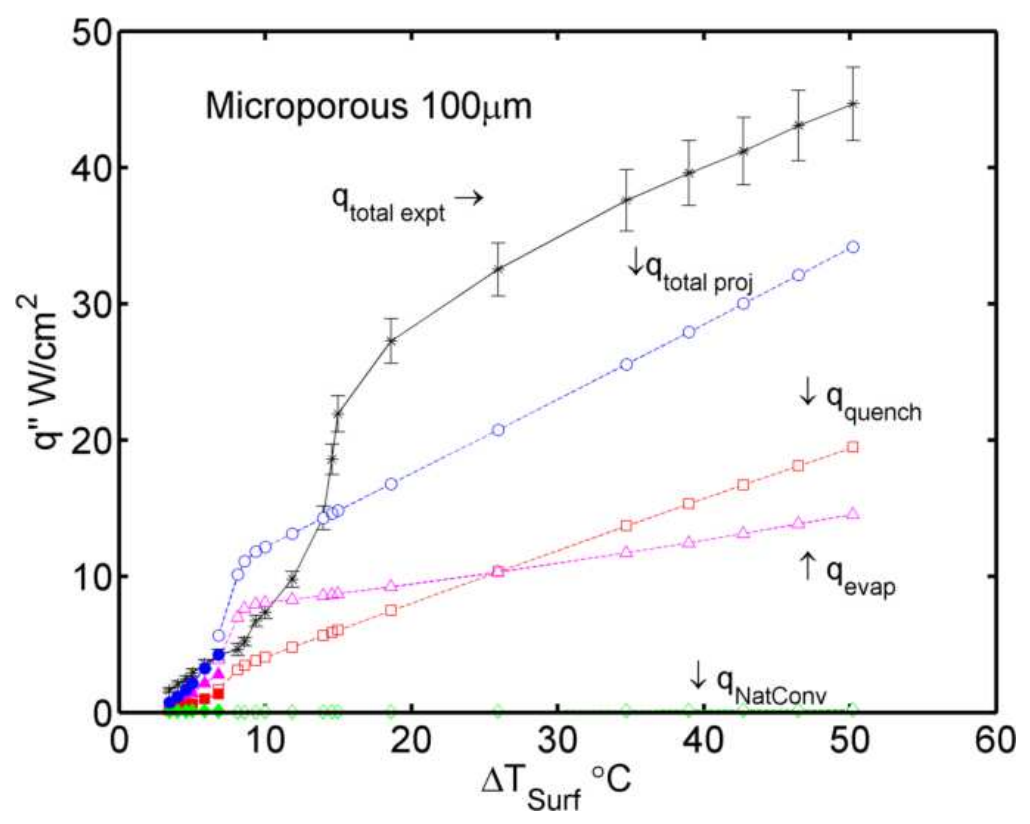

1

2 Fig. 15. The partition of heat flux model applied to the microporous surfaces: (a) $700 \mu \mathrm{m}$, (b)

$3 \quad 360 \mu \mathrm{m}$, and (c) $100 \mu \mathrm{m}$. The solid line with * markers is the experimental data. The solid

4 markers denote the data points of $N, D$, and $f$ from experiments, and the open symbols denote the 5 data from extrapolated $N, D$, and $f$.

6 
1. TITLE OF THE PAPER

Bubble dynamics and nucleate pool boiling heat transfer on microporous copper surfaces

2. AUTHORS

i. Name:

Suraj Joottu Thiagarajan

Affiliation:

Department of Mechanical Engineering, University of Colorado Boulder.

Address:

Department of Mechanical Engineering

427 UCB University of Colorado

1111 Engineering Drive

Boulder, CO 80309-0427, U.S.A.

Email: $\quad$ Suraj.Thiagarajan@Colorado.edu

Phone: 1-720-505-9517.

ii. Name:

Ronggui Yang (Corresponding author)

Affiliation:

Department of Mechanical Engineering, University of Colorado Boulder.

Address:

Department of Mechanical Engineering

427 UCB University of Colorado

1111 Engineering Drive

Boulder, CO 80309-0427, U.S.A.

Email: $\quad$ Ronggui.Yang@Colorado.edu

Phone: 1-303-735-1003

Fax: $\quad$ 1-303-492-3498.

iii. Name:

Charles King

Affiliation:

National Renewable Energy Laboratory, Golden, CO

Address:

National Renewable Energy Laboratory,

15013 Denver West Parkway,

Golden, CO, 80401, U.S.A.

Email: $\quad$ Charles.King@NREL.gov

Phone: 1-303-275-4419

iv. Name: Sreekant Narumanchi (Corresponding author)

Affiliation: National Renewable Energy Laboratory, Golden, CO

Address: $\quad$ National Renewable Energy Laboratory,

15013 Denver West Parkway,

Golden, CO, 80401, U.S.A.

Email: $\quad$ Sreekant.Narumanchi@NREL.gov

Phone: 1-303-275-4062

Fax: $\quad$ 1-303-275-4415. 